NBER WORKING PAPER SERIES

\title{
DIRECTED SEARCH OVER THE LIFE CYCLE
}

\author{
Guido Menzio \\ Irina A. Telyukova \\ Ludo Visschers \\ Working Paper 17746 \\ http://www.nber.org/papers/w17746
NATIONAL BUREAU OF ECONOMIC RESEARCH
1050 Massachusetts Avenue
Cambridge, MA 02138
January 2012

We have benefited from the insights of Pierre Cahuc, Jean-Olivier Hairault, Greg Kaplan, John Kennan, Richard Rogerson and Henry Siu. We have also received useful comments from participants at the macro seminar at UC Santa Cruz, Mainz, Freiburg, Konstanz, Bogazici, METU, Carlos III, the Essex conference in honor of Ken Burdett (Essex 2010), the NBER Summer Institute (Cambridge 2010), the Canadian Macro Study Group (London 2010), the Society for Economic Dynamics Meeting (Montreal 2010), the Royal Economic Society Meeting (London 2010), the workshop on Labor Market Transitions over the Lifecycle (Paris 2011). Visschers acknowledges financial support from the Simon Fraser University's President's Research Grant, the Spanish Ministry of Science and Innovation grant ECO2010/20614, the Bank of Spain's Programa de Excelencia Grant, and the Juan de la Cierva Grant. The views expressed herein are those of the authors and do not necessarily reflect the views of the National Bureau of Economic Research.

NBER working papers are circulated for discussion and comment purposes. They have not been peerreviewed or been subject to the review by the NBER Board of Directors that accompanies official NBER publications.

(C) 2012 by Guido Menzio, Irina A. Telyukova, and Ludo Visschers. All rights reserved. Short sections of text, not to exceed two paragraphs, may be quoted without explicit permission provided that full credit, including $\left({ }^{\circ}\right.$ notice, is given to the source. 
Directed Search over the Life Cycle

Guido Menzio, Irina A. Telyukova, and Ludo Visschers

NBER Working Paper No. 17746

January 2012

JEL No. E24,J63,J64

\begin{abstract}
$\underline{\text { ABSTRACT }}$
We develop a life-cycle model of the labor market in which different worker-firm matches have different quality and the assignment of the right workers to the right firms is time consuming because of search and learning frictions. The rate at which workers move between unemployment, employment and across different firms is endogenous because search is directed and, hence, workers can choose whether to seek low-wage jobs that are easy to find or high-wage jobs that are hard to find. We calibrate our theory using data on labor market transitions aggregated across workers of different ages. We validate our theory by showing that it correctly predicts the pattern of labor market transitions for workers of different ages. Finally, we use our theory to decompose the age profiles of transition rates, wages and productivity into the effects of age variation in work-life expectancy, human capital and match quality.
\end{abstract}

\author{
Guido Menzio \\ Department of Economics \\ University of Pennsylvania \\ 467 McNeil Building \\ 3718 Locust Walk \\ Philadelphia, PA 19104 \\ and NBER \\ gmenzio@econ.upenn.edu \\ Irina A. Telyukova \\ UCSD Department of Economics \\ 9500 Gilman Drive, MC 0508 \\ La Jolla, CA 92093-0508 \\ itelyukova@ucsd.edu
}

Ludo Visschers

Department of Economics

Universidad Carlos III, Madrid

Calle Madrid 126, Getafe 28903

Spain

lvissche@eco.uc3m.es 


\section{Introduction}

The US economy displays a great deal of labor reallocation, in the sense that workers move frequently between employment, unemployment and across different employers. For example, the rate at which unemployed workers become employed (henceforth, the UE rate) is close to 25 percent per month, the rate at which employed workers become unemployed (the EU rate) is approximately 0.5 percent per month, and the rate at which workers move from one employer to another (the EE rate) is approximately 1.8 percent per month. ${ }^{1}$ However, these aggregate transition rates hide dramatic differences in the extent of labor reallocation for workers of different ages. For example, among workers of age 20 to 25, the monthly UE rate is 28 percent, the EU rate is 1.5 percent and the EE rate is 3.5 percent. Among workers of age 40 to 45 , the monthly UE rate is 25 percent, the EU rate is 0.4 percent and the EE rate is 1.8 percent. And among workers of age 55 to 60, the monthly UE, EU and EE rates are, respectively, 18 percent, 0.2 percent and 1.5 percent.

The purpose of this paper is to explain the differences in the extent and pattern of labor reallocation of young, middle-aged and old workers. To this end, we develop a life-cycle model of the labor market in which different worker-firm matches have different productivity and the allocation of the right workers to the right firms is a time consuming process because of search and learning frictions. On one side of the labor market, firms choose how many and what type of vacancies to open, where the type of a vacancy is defined by the conditions under which it hires a worker and by the value of the employment contract that it offers to a new hire. On the other side of the labor market, both employed and unemployed workers choose which type of vacancy to seek. In this sense, the search process is directed. The workers and the firms who seek and offer the same type of vacancy come together through a frictional process described, in reduced form, by a constant return to scale matching function. When workers and firms match, they begin production and eventually learn the quality of their union.

In equilibrium, all workers face a choice between searching for vacancies that offer relatively higher wages and searching for vacancies that are relatively easier to find. The choices

\footnotetext{
${ }^{1}$ The figures reported in this introduction are constructed from the 1996 panel of the U.S. Census' Survey of Income and Program Participation (SIPP) for men with a high school degree. We refer the reader to Section 3 for further details about the data.
} 
faced by a particular worker depend on his age and experience. Specifically, if the age and experience of the worker make him a more valuable production partner, he will face a higher probability of finding vacancies offering any value. The preferences of a particular worker over the probability of finding a vacancy and the value offered by a vacancy depend on the worker's employment position (i.e., unemployment or employment in a match of a given quality). Specifically, if the worker is in a more valuable employment position, he will have a stronger preference for vacancies that offer higher value and are harder to find. Overall, the age, experience and employment position of a worker determine his optimal search strategy and, consequently, the velocity at which he moves across employment states.

We calibrate the model using aggregate data on labor reallocation, such as the unconditional mean of the UE, EU and EE rates and the mean of the EU and EE rates conditional on tenure. The calibration reveals that there is a great deal of heterogeneity in the quality of firm-worker formed matches. For example, a match in the 90th percentile of the quality distribution is approximately 3 times more productive than a match in the 10th percentile. The search frictions that slow down the process of assignment of the right workers to the right firms are modest, in the sense that workers are almost always able to search the labor market and that firms pay a relatively small cost to open new vacancies. For example, the expected vacancy cost that a firm has to incur to hire a middle-aged unemployed worker is approximately equal to 2 months of the worker's output. Similarly, the learning frictions are modest, in the sense that firms and workers learn rather quickly the quality of their match. On average, it takes 4 months for a firm and a worker to learn the quality of their match. Overall, the large heterogeneity in match quality and the modest search and learning frictions add up to generate a rather time-consuming process of assignment of the right workers to the right firms.

In order to validate the calibrated model, we use data on labor reallocation disaggregated according to the workers' age. In particular, we show that the calibrated model correctly predicts the mean of the UE, EU and EE transition rates conditional on the workers' age. We then use the model to decompose the overall effect of age on the transition rates into the effect of three characteristics that differ between older and younger workers: work-life expectancy, ${ }^{2}$ experience and selection into matches of different quality. We find that the

\footnotetext{
${ }^{2}$ Throughout the paper, we define work-life expectancy as the expected time before a worker exits the
} 
decline in the UE rate experienced by workers between the ages of 50 and 65 (see Figure 1) is mainly due to the decline in the workers' work-life expectancy, which reduces their value to the firms as production partners. We find that the decline in the EU rate experience by workers between the ages of 20 and 30 (see Figure 2) is mostly due to their transition from low to high quality matches, which reduces their incentive to move into unemployment. Moreover, we find that the steady decline in the EE rate that takes place throughout the life cycle (see Figure 3) is caused initially by the increase in the quality of the workers' matches and later by the decline in the workers' work-life expectancy.

Finally, we use the model to identify the causes of productivity and wage growth over the life cycle. We find that almost all of the life-cycle growth in labor productivity takes place during the first ten years of the work-life, and that approximately 76 percent of this growth is due to increases in the workers' experience and 24 percent is due to improvements in the quality of the workers' matches. Similarly, we find that almost all of the life-cycle growth in wages takes place early in a worker's career. Approximately 75.9 percent of this wage growth is due to increases in workers' experience, 23.9 percent is due to increases in the quality of the workers' matches and only 0.2 percent is due to improvements in the terms of the workers' employment contracts.

Our paper contributes to three strands of literature. First, the paper contributes to the literature on directed search pioneered by Montgomery (1991), Moen (1997), Shimer (1996) and Burdett, Shi and Wright (2001) and recently developed by Albrecht, Gautier and Vroman (2006), Shi (2009), Galenianos and Kircher (2010), Eeckhout and Kircher (2010) and Menzio and Shi (2011). Relative to the existing literature, we are the first to introduce workers' age and experience heterogeneity in a model of directed search on the job. In equilibrium, we find that workers' characteristics and employment status affect the resolution of the trade-off between the probability of finding a vacancy and the value offered by a vacancy. Moreover, we show that these effects are sufficient to reproduce the empirical age profile of the workers' transitions between employment, unemployment and across different employers. We also generalize the theoretical results in Menzio and Shi (2011) by proving that the unique equilibrium is block recursive and efficient.

labor market. 
Second, our paper contributes to the literature that studies the pattern of workers' transitions across employment states over the life cycle. Cheron, Hairault and Langot (2007, 2011) develop a life-cycle version of the search model by Mortensen and Pissarides (1994). The paper assumes that search is random and that the quality of a match is drawn independently and identically in every period (i.e. match quality is i.i.d.) and is observed without delay (i.e. matches are inspection goods). While these assumptions afford the authors an elegant closed-form analysis and powerful insights into the behavior of the model, they also generate a number of counterfactual predictions. First, these assumptions imply that the EU rate should be increasing with age, while, in the US data, the EU rate is clearly decreasing with age. Second, these assumptions imply that the exit rate from a job should be increasing with tenure, while, in the US data, the exit rate is sharply decreasing with tenure, suggesting that matches are not inspection goods but experience goods. Esteban-Pretel and Fujimoto (2011) build on Chéron, Hairault and Langot (2007) by introducing a persistent component to match quality that, with some probability, is observed before the creation of the match (i.e. matches are partly inspection and partly experience goods and their quality is persistent). While the model matches quite well the age profile of the UE and EU rates, it only does so under the assumption that matches between firms and older workers are more likely to be inspection goods. In contrast, our model correctly predicts the age profile of the UE, EU and EE rates not because the matching technology varies with age, but because the resolution of the directed search trade-off between the probability of finding a vacancy and the value offered by a vacancy varies with age.

Finally, our paper contributes to the literature that combines search frictions and human capital accumulation in an attempt to identify the causes of productivity and wage growth over the life cycle. Bagger, Fontaine, Postel-Vinay and Robin (2006) develop and quantify a human capital version of the random search model with dynamic auction model by PostelVinay and Robin (2001, 2002). While their model is quite different from ours, their main findings are similar to ours. In particular, they find that most of the wage growth takes place during the first 10 years of labor market experience, and that approximately 60 percent of this growth is due to human capital accumulation and 40 percent is due to search frictions. Fu (2011) and Burdett, Carrillo-Tudela and Coles (2011) and Burdett and Coles (2011) develop human capital versions of the model of random search on the job by Burdett and 
Mortensen (1998). These papers are mainly theoretical, and do not offer a decomposition of wage growth. Moreover, because they assume that experience increases market and home productivity proportionally, the models in these papers can be solved analytically, but have counterfactual implications regarding workers' transition rates. For example, they imply that the UE and EU rates are independent of age.

The remainder of the paper is structured as follows. In Section 2, we develop our life-cycle theory of labor reallocation. In particular, we lay out the environment, define equilibrium, prove the existence, uniqueness and efficiency of the equilibrium and characterize the effect of work-life expectancy, experience and match quality on the workers' policy functions. In Section 3, we describe the data that we use to calibrate and validate our theory. In Section 4, we quantify and apply our life-cycle theory of labor reallocation. In particular, we calibrate and validate the model, and we decompose the age profiles of the workers' transition rates, productivity and wages. Section 5 concludes.

\section{Lifecycle theory of labor reallocation}

In this section, we develop a life-cycle model of the labor market with search and learning frictions in the spirit of Menzio and Shi (2011). On one side of the market, firms choose how many and what type of vacancies to open, where the type of a vacancy is defined by the conditions under which it hires a worker and by the value of the employment contract that it offers to a new hire. On the other side of the labor market, workers choose the type of vacancy towards which they direct their search. Due to the presence of search frictions, it takes time for a worker to find the type of vacancy he seeks. Due to the presence of learning frictions, it takes time for a firm and a worker to learn the quality of their match. Because the search process is directed, the velocity at which a worker moves across different employment states (i.e. employment, unemployment and across different employers) depends on his age, human capital and his current employment position. First, these characteristics affect the trade-off that the worker faces between the value offered by a vacancy and the probability of finding that vacancy. Second, these characteristics affect the worker's preferences over the value offered by a vacancy and the probability of finding it. Overall, the worker's characteristics determine whether the worker will seek vacancies that offer him lower wages but are easier 
to find or vacancies that offer more generous wages but are harder to find.

\section{$2.1 \quad$ Environment}

The economy is populated by $T$ overlapping generations of workers. In every period, a new generation of workers is born into the economy and lives for $T$ periods, where $T \geq 2$ is an integer. Each worker is endowed with one indivisible unit of labor. Each worker maximizes the expected sum of periodical consumption discounted at the factor $\beta \in(0,1)$. The economy is also populated by a continuum of firms with positive measure. Each firm operates a constant return to scale technology that turns one unit of labor into $z g(y)$ units of output. The first component of productivity, $z$, is specific to the firm-worker pair, and its value lies in the set $Z=\left\{z_{1}, z_{2}, \ldots z_{N(z)}\right\}$, where $0<z_{1}<z_{2}<\ldots z_{N(z)}$ and $N(z) \geq 2$ is an integer. The second component of productivity, $g(y)$, is specific to the worker. Specifically, $y \in \mathbb{N}$ denotes the experience of the worker (i.e. the number of periods in which the worker has been employed) and $g: \mathbb{N} \rightarrow \mathbb{R}_{+}$is an increasing and concave function. Each firm maximizes the expected sum of periodical profits discounted by the factor $\beta$.

The labor market is organized in a continuum of submarkets indexed by the triple $(x, y, t) \in \mathbb{R} \times \mathbb{N}^{2}$. Different submarkets differ with respect to the terms of trade offered by the firms and with respect to the supply and demand conditions. Specifically, in submarket $(x, y, t)$, firms hire workers of age $t$ and experience $y$ and offer them employment contracts worth $x$ in lifetime utility. ${ }^{3}$ We refer to $(y, t)$ as the type of the worker. Moreover, in submarket $(x, y, t)$, the ratio of firms searching for workers to workers searching for firms is $\theta_{t}(x, y)$. Following Pissarides 1985, we refer to $\theta_{t}(x, y)$ as the tightness of submarket $(x, y, t)$.

Time is discrete and continues forever. At the beginning of each period, the aggregate state of the economy can be summarized by the tuple $\psi=(n, u, e, \gamma)$. The first component of $\psi$ is a function $n: \mathbb{N} \rightarrow \mathbb{R}_{+}$, where $n(t)$ denotes the measure of workers that have yet to enter the labor market. We refer to these workers as non-participating. The second component is a function $u: \mathbb{N}^{2} \rightarrow \mathbb{R}_{+}$, where $u(y, t)$ denotes the measure of workers of type $(y, t)$ who are in the labor market but are not employed. We refer to these workers as unemployed. The third

\footnotetext{
${ }^{3}$ In many countries, it is illegal for firms to discriminate workers based on age. However, firms can circumvent these legal restrictions by rejecting applicants based on age and claiming that they have been rejected based on quality.
} 
component is a function $e:\left\{z_{0} \cup Z\right\} \times \mathbb{N}^{2} \rightarrow \mathbb{R}_{+}$, where $e(z, y, t)$ denotes the measure of workers of type $(y, t)$ who are employed in a match of known quality $z$, and $e\left(z_{0}, y, t\right)$ denotes the measure of workers of type $(y, t)$ who are employed in a match of unknown quality. We refer to employed and unemployed worker as participating workers. Finally, $\gamma \in \mathbb{R}_{+}$denotes the current realization of the stochastic process for the measure of newly born workers. ${ }^{4}$

Every period is divided into five stages: entry-and-exit, separation, search, matching and production. At the first stage, a non-participating worker of age $t$ enters the labor market with probability $\mu_{t} \in[0,1]$. Similarly, a participating worker of age $t$ permanently exits the labor market with probability $1-\nu_{t}, \nu_{t} \in[0,1]$. Without loss in generality, we assume $\nu_{T+1}=0$.

At the separation stage, an employed worker becomes unemployed with probability $d \in$ $[\delta, 1]$, where $d$ is a probability determined by the worker's employment contract and $\delta \in[0,1]$ is the probability that the worker has to leave his job for exogenous reasons.

At the search stage, a worker has the opportunity to search the labor market with a probability that depends on his employment state. In particular, if a worker is unemployed at the beginning of the separation stage, he has the opportunity to search with probability $\lambda_{u} \in(0,1]$. If a worker is employed at the separation stage and has not lost his job, he has the opportunity to search with probability $\lambda_{e} \in(0,1]$. And if the worker lost his job during the separation stage, he cannot search in the current period. Whenever a worker has the opportunity to search, he chooses which submarket to visit. Also, during the search stage, a firm chooses how many vacancies to create in each submarket. The cost of maintaining a vacancy for one period is $k>0$.

At the matching stage, the vacancies and the workers who are searching in the same submarket come together through a frictional matching process. In particular, a worker

\footnotetext{
${ }^{4}$ In existing lifecycle models of labor market search (see e.g. Cheron, Hairault and Langot 2007, Burdett, Carrillo-Tudela and Coles 2011 and Esteban-Pretel and Fujimoto 2011), the distribution of workers across ages is a state variable of the aggregate economy which non-trivially affects the individual agents' value and policy functions. For this reason, these models have only been solved under the counterfactual assumption that the population growth rate is constant over time and that the economy is in a steady-state. In our model, the equilibrium is block recursive, in the sense that the distribution of workers across ages does not affect the individual agents' value and policy functions. Hence, we can solve our model even when the population growth rate is allowed to follow a stochastic random process. As discussed in Menzio and Shi (2010), the equilibrium of our model is block recursive because we replaced the assumption of random search with the assumption of directed search.
} 
searching in submarket $(x, y, t)$ meets a vacancy with probability $p\left(\theta_{t}(x, y)\right)$, where $p: \mathbb{R}_{+} \rightarrow$ $[0,1]$ is a twice-differentiable, strictly increasing and strictly concave function with boundary conditions $p(0)=0$ and $p(\infty)=1$. Similarly, a vacancy searching in submarket $(x, y, t)$ meets a worker with probability $q\left(\theta_{t}(x, y)\right)$, where $q: \mathbb{R}_{+} \rightarrow[0,1]$ is a twice-differentiable strictly decreasing function such that $q(\theta)=p(\theta) / \theta, q(0)=1$ and $q(\infty)=0$. When a firm and a worker of type $(y, t)$ meet in submarket $(x, y, t)$, the firm offers to the worker an employment contract that is worth $x$ in lifetime utility. If the worker rejects the offer, he returns to his previous employment position (i.e. unemployment or employment at another firm). If the worker accepts the offer, he leaves his previous employment position and enters a productive match with the firm. At the end of the matching stage, nature draws the productivity of a newly formed match from the distribution $f(z)$. Moreover, with probability $\eta \in[0,1]$, nature draws a new realization for the productivity of an existing match from the distribution $f(z)$. We assume that matches are experience goods, in the sense that firms and workers do not immediately observe the realized value of $z$.

At the production stage, an unemployed worker of type $(y, t)$ produces and consumes $b$ units of output. A worker of type $(y, t)$ who is employed in a match of quality $z$ produces $z g(y)$ units of output and consumes $w$ of them, where $w$ is the wage specified by the worker's employment contract. The worker and the firm observe their output with probability $\alpha \in$ $(0,1]$. At the end of the production stage, nature draws the measure of next period's entering cohort from the distribution $\Pi(\hat{\gamma} \mid \gamma), \Pi: \mathbb{R}_{+} \rightarrow \mathbb{R}_{+}$. Throughout the paper, the caret indicates variables or functions in the next period.

To conclude the description of the model, we need to specify the details of the contractual environment. In this paper, we assume that employment contracts are complete, in the sense that they can specify the wage paid by the firm to the worker, $w$, the probability that the worker and the firm break up at the separation stage, $d$, and the submarket where the worker should search while employed by the firm, $\left(x_{e}, y, t\right)$, as a function of the history of the firm-worker match and of the aggregate economy.

Given the assumption of complete contracts and the fact that utility is perfectly transferrable, it is easy to prove that the firms always find it optimal to offer employment contracts that are bilaterally efficient, in the sense that these contracts maximize the sum of 
the worker's lifetime utility and the firm's lifetime profits from forming a match. This result is formally established in Menzio and Shi (2011) and is easy to understand. A firm in submarket $(x, y, t)$ maximizes its profits by offering an employment contract such that the contingencies for $d$ and $x_{e}$ deliver bilateral efficiency and the contingencies for $w$ deliver the value $x$ to the worker. Clearly, there are many contingencies for $w$ that deliver the same value $x$ to the worker. The value $x$ can be delivered through a wage that remains constant throughout the duration of the employment relationship, by a wage that varies with the worker's tenure, or by a wage that varies with the worker's productivity. ${ }^{5}$ For the purposes of the theoretical part of the paper, we do not need to resolve this indeterminacy. In the empirical part of the paper, we will assume that wages are set as a constant fraction of the worker's productivity. We shall refer to this constant fraction as the worker's piece-rate. ${ }^{6}$

At this point, it is useful to briefly discuss the main assumptions in our model. First, we assume that firms post the terms of the employment contract and workers can direct their search towards firms offering a specific contract. We make this assumption because we are interested in finding out whether a model in which the search process is directed is able to reproduce the life-cycle patterns of labor reallocation that we observe in the US data. Second, we assume that firms post employment contract for only one type of worker rather than a menu of contracts for all possible types of workers. This assumption is without loss in generality. In fact, Menzio and Shi (2010b) show that, when firms are allowed to offer menus of contracts, they find it optimal to choose menus that attract exclusively one type of worker. Third, we assume that firms can discriminate applicants based on their age and experience, but not on their current employment state (e.g. whether the applicant is currently

\footnotetext{
${ }^{5}$ In most search models with risk-neutral workers and firms, wages can only be pinned down with the help of somewhat arbitrary assumptions about the process of wage determination. For example, in Pissarides (1985) and Mortensen and Pissarides (1994), wages would not be uniquely pinned down if not for the arbitrary assumption that wages need to be renegotiated in every period. In Postel-Vinay and Robin (2002), wages would not be uniquely pinned down if not for the assumption that firms are constrained to offer wages that remains constant until the employee receives an outside offer.

${ }^{6}$ We have carried out quantitative analysis of the model under two alternative specifications of the wage determination process: a fixed-wage process and an incentive compatible process. In the case of the fixedwage process, we assume that the wage remains constant throughout the entire duration of the employment relationship. In the case of the incentive compatible process, we assume that the wages are such that the worker finds it optimal to choose the separation and search strategies prescribed by the bilaterally efficient contract. That is, the incentive compatible process implements the prescriptions of the bilaterally efficient contract without requiring any commitment from the worker. We found that the quantitative predictions of the model under these two alternative specifications of the wage determination process are very close to those obtained for the piece-rate process.
} 
unemployed or employed in a match of a particular quality). This assumption is common in the literature on search on the job. For example, Van den Berg and Ridder (1998) and Burdett, Carrillo-Tudela and Coles (2011) allow contracts to depend on the applicant's skill and experience but not on his employment state. In general, this assumption is motivated by the view that an applicant's age, skill and experience are characteristics that can be easily verified by a prospective employer, while an applicant's current employment status is not. Fourth, we assume that employment contracts are complete. We find this assumption appealing not because we literally believe that firms and workers sign complete contracts, but because we hold the view that matched firms and workers will find a way to behave so as to maximize their joint gains from trade. ${ }^{7}$

\subsection{Definition of Equilibrium}

First, consider a worker of type $(y, t)$ who is unemployed at the beginning of the production stage. The worker's lifetime utility $U_{t}(y, \psi)$ is such that

$$
U_{t}(y, \psi)=b+\beta \mathbb{E}_{\hat{\psi} \mid \psi}\left[U_{t+1}(\hat{y}, \hat{\psi})+\lambda_{u} R_{t+1}(\hat{y}, \hat{\psi})\right]
$$

where $\hat{y}=y$ and

$$
R_{t+1}(\hat{y}, \hat{\psi})=\max _{x} p\left(\theta_{t+1}(x, \hat{y}, \hat{\psi})\right)\left[x-U_{t+1}(\hat{y}, \hat{\psi})\right]
$$

In the current period, the worker produces and consumes $b$ units of output. In the next period, the worker gets the opportunity to search the labor market with probability $\lambda_{u}$. In this case, the worker's continuation utility is $U_{t+1}(\hat{y}, \hat{\psi})+R_{t+1}(y, \hat{\psi})$, where $R_{t+1}(y, \hat{\psi})$ is the maximum with respect to $x$ of the probability that the worker finds a job, $p\left(\theta_{t+1}(x, y, \hat{\psi})\right)$, times the value to the worker from finding a job, $x-U_{t+1}(\hat{y}, \hat{\psi})$. With probability $1-\lambda_{u}$, the worker does not have the opportunity to search in the next period. In this case, the worker remains unemployed and his continuation utility is $U_{t+1}(y, \hat{\psi})$. We denote as $x_{t+1}^{u}(\hat{y}, \hat{\psi})$ the policy function associated with (1).

Second, consider a firm and a worker of type $(y, t)$ who are in a match of known quality

\footnotetext{
${ }^{7}$ In the model, we completely abstract from the funding and payment of unemployment and retirement benefits. As discussed in Zhao and Faig (2012), this abstraction is approximately innocuous as long as workers are not too far from risk neutral and unemployment and retirement benefits are funded according to a scheme that is not too far from actuarially fair.
} 
$z$ at the beginning of the production stage. The sum of the worker's lifetime utility and the firm's lifetime profits, $V_{t}(z, y, \psi)$, is such that

$$
\begin{aligned}
& V_{t}(z, y, \psi)=z g(y) \\
& \quad+\beta \mathbb{E}_{\hat{\psi} \mid \psi} \max _{d \in[\delta, 1]}\left\{d U_{t+1}(\hat{y}, \hat{\psi})+(1-d)\left[\mathbb{E}_{\hat{z} \mid z} V_{t+1}(\hat{z}, \hat{y}, \hat{\psi})+\lambda_{e} S_{t+1}(z, \hat{y}, \hat{\psi})\right]\right\}
\end{aligned}
$$

where $\hat{y}=y+1$ and

$$
S_{t+1}(z, \hat{y}, \hat{\psi})=\max _{x} p\left(\theta_{t+1}(x, \hat{y}, \hat{\psi})\right)\left[x-\mathbb{E}_{\hat{z} \mid z} V_{t+1}(\hat{z}, \hat{y}, \hat{\psi})\right]
$$

In the current period, the sum of the worker's utility and the firm's profit is $z g(y)$, the output of the match. At the separation stage of next period, the worker becomes unemployed with probability $d$. In this case, the sum of the worker's continuation utility and the firm's continuation profit is $U_{t+1}(\hat{y}, \hat{\psi})$. At the search stage of next period, the worker does not have the opportunity to search the labor market with probability $1-\lambda_{e}$. In this case, the worker and firm remain matched and the sum of their continuation values is $\mathbb{E}_{\hat{z} \mid z} V_{t+1}(\hat{z}, \hat{y}, \hat{\psi})=$ $\eta V_{t+1}\left(z_{0}, \hat{y}, \hat{\psi}\right)+(1-\eta) V_{t+1}(z, \hat{y}, \hat{\psi})$, where $\gamma$ is the probability that the match is hit by a quality shock and $V_{t+1}\left(z_{0}, \hat{y}, \hat{\psi}\right)$ is the value to the firm and the worker from a match of unknown quality. At the search stage of next period, the worker gets the opportunity to search the labor market with probability $\lambda_{e}$. In this case, the sum of the worker's continuation utility and the firm's continuation profit is $S_{t+1}(z, \hat{y}, \hat{\psi})+\mathbb{E}_{\hat{z} \mid z} V_{t+1}(\hat{z}, \hat{y}, \hat{\psi})$. We denote as $d_{t+1}(z, \hat{y}, \hat{\psi})$ and $x_{t+1}^{e}(z, \hat{y}, \hat{\psi})$ the policy functions associated with $(2)$.

Third, consider a firm and a worker of type $(y, t)$ who are in a match of unknown quality at the beginning of the production stage. The sum of the worker's lifetime utility and the firm's lifetime profits, $V_{t}\left(z_{0}, y, t\right)$, is such that

$$
\begin{aligned}
& V_{t}\left(z_{0}, y, \psi\right)=\alpha \sum_{z} V_{t}(z, y, \psi) f(z)+(1-\alpha) \sum_{z} z h(y) f(z) \\
& \quad+(1-\alpha) \beta \mathbb{E}_{\hat{\psi} \mid \psi} \max _{d \in[\delta, 1]}\left\{d U_{t+1}(\hat{y}, \hat{\psi})+(1-d)\left[\mathbb{E}_{\hat{z} \mid z_{0}} V_{t+1}(\hat{z}, \hat{y}, \hat{\psi})+\lambda_{e} S_{t+1}\left(z_{0}, \hat{y}, \hat{\psi}\right)\right]\right\}
\end{aligned}
$$

With probability $\alpha$, the firm and the worker observe the quality of their match in the current period. In this case, the expected sum of the worker's lifetime utility and the firm's lifetime profit is $\sum_{z} V_{t}(z, y, \psi) f(z)$. With probability $1-\alpha$, the firm and the worker do not discover the quality of their match in the current period. In this case, the sum of the worker's lifetime utility and the firm's lifetime profit is given by the second line of (3), which is the analogue 
of (2) for a match of unknown quality. We denote as $d_{t+1}\left(z_{0}, \hat{y}, \hat{\psi}\right)$ and $x_{t+1}^{e}\left(z_{0}, \hat{y}, \hat{\psi}\right)$ the policy functions associated with (3).

Finally, the tightness of the submarket is such that

$$
k \geq q\left(\theta_{t}(x, y, \psi)\right)\left[V_{t}\left(z_{0}, y, \psi\right)-x\right]
$$

and $\theta_{t}(x, y, \psi) \geq 0$ with complementary slackness. The above condition guarantees that the tightness function $\theta_{t}$ is consistent with the firm's incentive to create vacancies. The cost to a firm from opening a vacancy in submarket $(x, y, t)$ is given by $k$. The benefit to a firm from opening a vacancy in submarket $(x, y, t)$ is given by the product between the probability that the firm fills the vacancy, $q\left(\theta_{t}(x, y, \psi)\right)$, and the value to the firm from filling the vacancy, $V_{t}\left(z_{0}, y, \psi\right)-x$. Condition (4) states that, if the vacancy-to-applicant ratio in submarket $(x, y, t)$ is strictly positive, the cost from opening a vacancy must be equal to the benefit. Moreover, condition (4) states that, if the vacancy-to-applicant ratio in submarket $(x, y, t)$ is equal to zero, the cost to a firm from opening a vacancy must be smaller or equal to the benefit.

We are now in the position to define a Block Recursive Equilibrium (see Shi 2009 and Menzio and Shi 2010, 2011).

Definition: A Block Recursive Equilibrium (BRE) consists of a market tightness function, $\theta_{t}$, a value function for the unemployed worker, $U_{t}$, a policy function for the unemployed worker, $x_{t}^{u}$, a value function for the firm-worker match, $V_{t}$, and a policy function for the firmworker match, $\left(d_{t}, x_{t}^{e}\right)$, for each $t=1,2, \ldots T$. These functions satisfy the following conditions: (i) $U_{t}, V_{t}, \theta_{t}, x_{t}^{u}, x_{t}^{e}$ and $d_{t}$ are independent of $\psi$; (ii) $\theta_{t}$ satisfies (4) for all $(x, y, \psi) \in \mathbb{R} \times \mathbb{N} \times \Psi$ and $t=1,2, \ldots T$; (iii) $U_{t}$ and $x_{t}^{u}$ satisfy (1) for all $y \in \mathbb{N}$ and $t=1,2, \ldots . T$; (iv) $V_{t}, d_{t}$ and $x_{t}^{e}$ satisfy (2) and (3) for all $(z, y, \psi) \in\left\{z_{0} \cup Z\right\} \times \mathbb{N} \times \Psi$ and $t=1,2, \ldots T$.

In words, a Block Recursive Equilibrium is a recursive equilibrium in which the agents' value and policy functions do not depend on the aggregate state of the economy $\psi$, which is given by the distribution of workers across age, experience and employment states, $(n, u, e)$, and the demographic shock, $\gamma$. Notice that a Block Recursive Equilibrium is much easier to solve than a recursive equilibrium. In fact, solving a recursive equilibrium amounts to solving a system of functional equations in which the unknown functions (i.e., the agents' 
value and policy functions) have at least $1+T+T^{2}(N(z)+2)$ arguments (i.e., the dimensions of the aggregate state $\psi$ ). In contrast, solving for a BRE amounts to solving for a system of functional equations in which the unknown value function have at most two arguments (i.e. the dimensions of the individual state $(z, y))$.

\subsection{Existence, uniqueness and efficiency of equilibrium}

Theorem 1: (i) The unique recursive equilibrium is a BRE. (ii) The BRE is socially efficient, in the sense that it generates the same allocation that solves the problem of a utilitarian social planner.

Proof: In the appendix.

Theorem 1 extends the results in Menzio and Shi (2011) to an economy in which workers are heterogeneous not only with respect to their employment status (e.g. unemployed or employed in a particular type of match) but also with respect to their age and experience. The economics behind Theorem 1 is the same as in Menzio and Shi (2011). The equilibrium is block recursive because search is directed. Intuitively, when search is directed, different workers find it optimal to search in different submarkets. As a result of this self-selection process, a firm opening a vacancy in a particular submarket knows that it will only meet applicants of a particular age, experience and employment status. Hence, the equilibrium tightness in that submarket will depend on neither the distribution of workers over age, experience and employment, nor on the demographic shock. Since the submarket tightness is independent of the distribution of workers and of the demographic shock, the agents' value and policy functions will have the same property. Moreover, the equilibrium is efficient because employment contracts are complete and the search is directed. Intuitively, the assumption of directed search guarantees that the creation of new matches is efficient and the assumption of complete contracts guarantees that the destruction of existing matches is efficient.

While the economics behind Theorem 1 is the same as in Menzio and Shi (2011), the existence proof is different. In Menzio and Shi (2011), workers are infinitely lived. For this reason, proving the existence and uniqueness of a BRE requires showing that the equilibrium conditions are a fixed point of an operator that: (a) maps the set of value functions that are 
independent of the workers' distribution into itself; (b) admits a unique fixed point. In this paper, workers are finitely lived. For this reason, we can prove the existence and uniqueness of a BRE by backward induction. From equations (1)-(3), it follows that the value functions for a worker of age $T$ does not depend on $\psi$. From equation (4), it follows that the tightness of a submarket $(x, y, T)$ does not depend on $\psi$. Since $V_{T}, U_{T}$ and $\theta_{T}$ are all independent of $\psi$, equations (1)-(3) imply that the value functions for a worker of age $T-1$ are independent of $\psi$, and equation (4) implies that the tightness of a submarket $(x, y, T-1)$ is independent of $\psi$. The argument can then be repeated to prove that all the other value and policy functions are also independent of $\psi$.

\subsection{Characterization of equilibrium}

The assumption of directed search implies that a worker searching for a job faces a tradeoff between the probability of receiving a job offer and the value offered by the job offer. The exact nature of the trade-off faced by a worker depends on his type (i.e. age and experience), as firms are willing to create more vacancies for those types of workers that make more productive (or, generally, more valuable) employees. The preferences of a worker over the probability and the value of a job offer depend on his current employment state (i.e. whether the worker is unemployed or employed in a match of a particular quality), as workers who are in more valuable states face a smaller downside risk in case they do not receive the offer. Overall, a worker's choice of which job offers to seek depends on his age, experience and employment state. Hence, the velocity at which a worker moves from unemployment to employment and from employer to employer also depends on his age, experience and employment state. Similarly, the velocity at which a worker moves from employment to unemployment depends on the value of his job relative to unemployment, which, in turn, depends on the worker's age and experience. From all these observations, it follows that, at the aggregate level, the velocity at which workers of different age reallocate depends on their distribution over experience and employment states. In the next paragraphs, we formalize the arguments above and characterize the transition probabilities of different workers.

From equation (4), it follows that a worker of type $(y, t)$ can choose to search in submarkets where the value offered by vacancies to applicants, $x$, and the ratio of vacancies to 
applicants, $\theta$, are such that

$$
x=p(\theta) V_{t}\left(z_{0}, y\right)-\frac{k}{q(\theta)} .
$$

The above equation states that, in a submarket with tightness $\theta$, a worker of type $(y, t)$ is offered a value $x$ which is equal to the difference between the value of a match between the worker and a firm, $V_{t}\left(z_{0}, y\right)$, and the expected vacancy cost that a firm has to incur to create a match with the worker, $k / q(\theta)$. Equation (5) implies that the worker faces a trade-off between the likelihood of receiving a job offer and the value of a job offer. In particular, the higher is the likelihood of receiving a job offer, $p(\theta)$, the lower is the value of a job offer, $x$. Moreover, equation (5) implies that different types of workers face a different trade-off between the likelihood and the value of a job offer. In particular, workers who generate more valuable matches are more likely to receive a job offer of any value $x$.

From equations (1)-(3), it follows that the preferences over $x$ and $\theta$ for a worker who is searching for a job are given by

$$
p(\theta)(x-v),
$$

where $v$ denotes the value of the worker's current employment state (i.e. $v$ equals $U_{t}(y)$ if the worker is unemployed and $\mathbb{E}_{\hat{z} \mid z} V_{t}(\hat{z}, y)$ if the worker is employed in a match of quality $z)$. The above expression implies that workers in different employment states have different preferences over the likelihood of receiving a job offer, $p(\theta)$, and the value of a job offer, $x$. In particular, the higher is the value of the worker's current employment state $v$, the stronger is the worker's preference for job offers that are relatively more generous and relatively harder to get. This property of the worker's preferences is intuitive, as workers who currently are in a better employment state face a smaller downside risk if they do not get the job offer they seek.

After substituting (5) into (6), we can write the search problem of a worker of type $(y, t)$ who is currently unemployed as

$$
\max _{\theta \geq 0} p(\theta)\left[V_{t}\left(z_{0}, y\right)-U_{t}(y)\right]-k \theta
$$

Similarly, we can write the search problem of a worker of type $(y, t)$ who is currently employed 
in a match of quality $z$ as

$$
\max _{\theta \geq 0} p(\theta)\left[V_{t}\left(z_{0}, y\right)-\mathbb{E}_{\hat{z} \mid z} V_{t}(\hat{z}, y)\right]-k \theta
$$

Equation (7) states that an unemployed worker chooses the tightness of the submarket where he looks for a job so as to maximize the probability that he finds a job, $p(\theta)$, times the surplus that he generates by finding a job, $V_{t}\left(z_{0}, y\right)-U_{t}(y)$, net of the cost of creating $\theta$ vacancies, $k \theta$. Similarly, equation (8) states that an employed worker chooses the tightness of the submarket where he looks for a new job so as to maximize the probability that he finds a new job, $p(\theta)$, times the surplus that he generates by finding a new job, $V_{t}\left(z_{0}, y\right)-\mathbb{E}_{\hat{z} \mid z} V_{t}(\hat{z}, y)$, net of the cost of creating $\theta$ vacancies, $k \theta$.

From (7), it follows that an unemployed worker of type $(y, t)$ finds it optimal to search in a submarket with tightness $\theta_{t}^{u}(y)$, where $\theta_{t}^{u}(y)$ is such that

$$
k \geq p^{\prime}\left(\theta_{t}^{u}(y)\right)\left[V_{t}\left(z_{0}, y\right)-U_{t}(y)\right]
$$

and $\theta_{t}^{u}(y) \geq 0$ with complementary slackness. Equation (9) implies that $\theta_{t}^{u}(y)$ depends on the surplus $V_{t}\left(z_{0}, y\right)-U_{t}(y)$ that the worker would generate if he were to find a job, which in turn depends on the worker's age $t$ and experience $y$. For the calibrated values of the parameters (see Table 1 ), we find that $V_{t}\left(z_{0}, y\right)-U_{t}(y)$ is increasing in $y$ and decreasing in $t$. These findings are intuitive. A higher $y$ increases $V_{t}\left(z_{0}, y\right)-U_{t}(y)$ because it increases the difference between the output of the worker in a job and at home. In contrast, a higher t reduces $V_{t}\left(z_{0}, y\right)-U_{t}(y)$ because it lowers the expected duration of the job. Given the properties of $V_{t}\left(z_{0}, y\right)-U_{t}(y)$, it follows from $(9)$ that $p\left(\theta_{t}^{u}(y)\right)$ - the probability that an unemployed worker becomes employed - is increasing in the worker's experience $y$ and decreasing in the worker's age $t$ (see Figure 4).

From (8), it follows that an employed worker of type $(y, t)$ finds it optimal to search in a submarket with tightness $\theta_{t}^{e}(z, y)$, where $\theta_{t}^{e}(z, y)$ is such that

$$
k \geq p^{\prime}\left(\theta_{t}^{e}(z, y)\right)\left[V_{t}\left(z_{0}, y\right)-\mathbb{E}_{\hat{z} \mid z} V_{t}(\hat{z}, y)\right]
$$

and $\theta_{t}^{e}(z, y) \geq 0$ with complementary slackness. Equation (10) implies that $\theta_{t}^{e}(z, y)$ depends on the surplus that the worker would generate if he were to find a job, $V_{t}\left(z_{0}, y\right)-\mathbb{E}_{\hat{z} \mid z} V_{t}(\hat{z}, y)$, 
which in turn depends on the worker's age, $t$, experience, $y$, and on the quality of his current job, z. It is easy to prove that $V_{t}\left(z_{0}, y\right)-\mathbb{E}_{\hat{z} \mid z} V_{t}(\hat{z}, y)$ is decreasing in $z$. However, it is difficult to characterize analytically the effect of $y$ and $t$ on $V_{t}\left(z_{0}, y\right)-\mathbb{E}_{\hat{z} \mid z} V_{t}(\hat{z}, y)$. For the calibrated version of the model, we find that the effect of the worker's experience $y$ on $V_{t}\left(z_{0}, y\right)-\mathbb{E}_{\hat{z} \mid z} V_{t}(\hat{z}, y)$ is positive if the worker is employed in a low-quality job, and negative if the worker is employed in a high-quality job. This finding is intuitive since experience increases (decreases) the difference between the worker's output in a new job and in a low (high) quality job. Similarly, we find that the effect of the worker's age $t$ on $V_{t}\left(z_{0}, y\right)-\mathbb{E}_{\hat{z} \mid z} V_{t}(\hat{z}, y)$ is negative if the worker is employed in a low-quality job and positive if the worker is employed in a high-quality job. This finding is also intuitive since age decreases (increases) the difference between the present value of the worker's output in a new job and in a low (high) quality job. From the properties of $V_{t}\left(z_{0}, y\right)-\mathbb{E}_{\hat{z} \mid z} V_{t}(\hat{z}, y)$, we conclude that an employed worker moves from job to job with a probability $p\left(\theta_{t}^{e}(z, y)\right)$ that is decreasing in the quality of his current job. Moreover, if the quality of his current job is sufficiently low, an employed worker moves from job to job with a probability $p\left(\theta_{t}^{e}(z, y)\right)$ that is increasing in the worker's experience and decreasing in the worker's age (see Figure 5).

Finally, we proceed to characterize the movements of workers from employment to unemployment. From (2), it follows that an employed worker of type $(y, t)$ moves into unemployment with probability $d_{t}(z, y)=1$ if

$$
U_{t}(y)>\lambda_{e} S_{t}(z, y)+\left(1-\lambda_{e}\right) V_{t}(z, y),
$$

and with probability $d_{t}(z, y)=\delta$ otherwise. The above expression is easy to understand. The left-hand side of (11) is the value that the worker and his employer enjoy if the worker moves into unemployment. The right-hand side of (11) is the value that the worker and his employer enjoy if the worker stays on the job. When the left-hand side is greater than the right-hand side, the worker and his employer find it optimal to separate with probability one. Otherwise, nature separates the worker and his employer with probability $\delta$. Notice that, since the right-hand side of (11) is strictly increasing in $z$ and the left-hand side of (11) is independent of $z$, the probability $d_{t}(z, y)$ can be represented by a reservation quality $r_{t}(y)$ such that $d_{t}(z, y)=1$ if $z<r_{t}(y)$ and $d_{t}(z, y)=\delta$ if $z \geq r_{t}(y)$. 
The reservation quality $r_{t}(y)$ depends on the worker's experience $y$ and age $t$. For the calibrated values of the parameters, we find that the reservation quality is increasing in $t$, it is hump-shaped in $y$ for relatively young workers and decreasing in $y$ for relatively old workers (see Figure 6). These findings are intuitive. A higher $t$ tends to lower the return on accumulating an additional month of experience by staying on the job and, through this channel, it tends to increase $r_{t}(y){ }^{8}$ A higher $y$ has two countervailing effects on $r_{t}(y)$. On the one hand, a higher $y$ tends to increase the difference between the worker's output in the job and at home and, hence, it tends to lower $r_{t}(y)$. On the other hand, since $h(y)$ is concave, a higher $y$ tends to lower the return from accumulating additional experience by staying on the job. Through this channel, a higher $y$ tends to increase $r_{t}(y)$. For young workers, the second effect dominates for low values of $y$ and the first effect dominates for high values of $y$. For older workers, the return to additional experience is low and, hence, the first effect always dominates.

\section{Labor reallocation data}

In this section, we describe the data that we use to calibrate and validate our model of labor reallocation over the life cycle. Moreover, we describe how, from these data, we construct the age profile of the workers' transition rates across different employment states, the tenure profile of the workers' transitions out of a job and the age profile of the workers' wage.

\subsection{Data and sample restrictions}

We use the U.S. Census' Survey of Income and Program Participation (SIPP) to calibrate and evaluate our model of labor reallocation over the life cycle. The SIPP is a longitudinal survey that follows the same individuals for periods up to four years. Each individual in the

\footnotetext{
${ }^{8}$ In models that abstract from search on the job and human capital accumulation, the separation decision involves a trade-off between the value of worker's production in the current match and the sum of the value of worker's home production and the option value of searching for a better match. In these models, the reservation quality $r_{t}(y)$ decreases with $t$ because the option value of searching is lower for older workers. In the calibrated version of our model, search on the job is almost as frequent as search off the job and human capital accumulation is important. Hence, in our calibrated model, the separation decision involves mainly a trade-off between the value of the worker's home production and the sum of the value of the worker's production in the current match and the value of accumulating an additional month of experience. In our models, the reservation quality $r_{t}(y)$ increases with $t$ because the value of experience is lower for older workers.
} 
survey is assigned to one of four rotation groups and is interviewed once every four months, in a staggered fashion, for the duration of the panel. When all rotation groups are interviewed, a wave of four months is completed, and a new wave is started with the interview of the first rotation group. Each interview collects data on the individual's income and employment status. For each week in the four months prior to the interview, the individual is asked whether he was working in a job, absent without pay, or looking for a job. If the individual reports to have had one or more job in a given month, he is asked about the identity of his employers and about his wage with each employer. If the individual had multiple jobs, we define as the dominant job the one where he worked the most hours. If the individual did not have a job and did not look for one, he is asked about the reason behind his non-participation (i.e. education, illness, discouragement, retirement).

We restrict attention to the 1996 panel of the SIPP, which spans the period from December 1995 to February 2000. Moreover, we restrict attention to men between the ages of 18 and 66 , who have a high school degree and do not own their own business. Given these sample restrictions, we are left with 10,554 individuals and 300,234 monthly observations. We choose to focus on individuals in a particular education group because the pattern of labor reallocation varies significantly among workers with different educational attainment, while these differences are not captured by our model. We choose to focus on individuals with a high school degree because they constitute the largest group in our data and because they are representative of the median US worker.

At the beginning of each month, we assign to each individual an employment status. To this end, we use the reports of the individual for the first week of the month. We classify the individual as employed (E) if he reports having a job and being either present or absent without pay, either on layoff or not. We classify the individual as unemployed (U) if he reports having no job, but looking for work actively or being on layoff. We classify the individual as not in the labor force $(\mathrm{N})$ if he reports having no job, not actively looking and not being on layoff. Further, we assign to each employed worker an employer and a wage, based on his dominant job. 


\subsection{Age profile of transitions within the labor force}

The main objective of this paper is explaining the empirical age profile of workers' transitions between employment, unemployment and across different employers. We construct these empirical age profiles as follows. First, we say that an individual experiences a UE transition in a given month if he is employed at the beginning of the month and employed at the beginning of next month. Similarly, we say that an individual experiences an EU transition if he is employed at the beginning of the month and unemployed at the beginning of the next month. And we say that an individual experiences an EE transition if he is employed at the beginning of the month and he is employed at some other firm at the beginning of next month. Hence, we disregard individual transitions that take place at a frequency higher than one month. We make this choice because, for computational tractability, our model period is chosen to be a month rather than a week. Next, we define the monthly UE transition rate for workers of a given age as the fraction of unemployed individuals of that age who experience a UE transition. Similarly, we define the monthly EU rate for workers of a given age as the fraction of employed workers of that age who experience an EU transition, and the monthly EE rate as the fraction of employed workers who experience an EE transition.

Figure 1 displays the raw and smoothed age profiles of the monthly UE rate. As one can see, the monthly UE rate is approximately constant at 25 percent for workers between the ages of 18 and 50, and it is sharply declining for workers older than 50. One can also see that the raw age profile becomes very noisy for workers older than 60 due to the small number of high school graduates who are unemployed late in their work life. In order to assess the robustness of the smoothed age profile for high school graduates, Figure 1 also displays the smoothed profile for the entire male population. Reassuringly, the two profiles are nearly on top of each other.

Figure 2 displays the raw and smoothed profiles of the monthly EU rate. As one can see, the monthly EU rate is downward sloping throughout the life cycle, with a slope that is markedly higher (in absolute value) for workers between the ages of 18 and 30 than for workers between the ages of 30 and 65 . The monthly EU rate is above 2 percent for 18 year

old workers, it is approximately 0.05 percent for 30 year old workers, and approximately 0.01 percent for 60 year old workers. Figure 2 also shows that the age profile of the EU rate for 
the entire male population is almost the same as the one for high-school graduates.

Figure 3 plots the raw and smoothed profiles of the monthly EE rate. As one can see, the monthly EE rate is downward sloping throughout the life cycle, but the slope varies less with age than the slope of the EU rate. The monthly EE rate is around 5 percent for 18 year old workers, it is approximately 2 percent for 35 year old workers, and approximately 1 percent for workers above the age of 60 . Figure 3 also shows that the age profile of the EE rate for the entire male population is almost the same as the one for high-school graduates. ${ }^{9}$

\subsection{Age profile of transitions in and out of the labor force}

There are not only large differences in the frequency at which young and old workers move between employment, unemployment and across different employers, but also large differences in the frequency at which young and old workers move in and out of the labor force. In order to construct the age profile of workers' transitions in and out of the labor force, we proceed as follows. First, we say that a worker experiences a transition into the labor force (a NL transition) if he is out of the labor force at the beginning of the month and either employed or unemployed at the beginning of next month. Similarly, we say that a worker experiences a transition out of the labor force (a LN transition) if he is either employed or unemployed at the beginning of the month and he is out of the labor force at the beginning of next month. Next, we define the NL transition rate for workers of a given age as the fraction of non-participating workers of that age that experience a NL transition. We define the LN rate for workers of a given age in an analogous way.

\footnotetext{
${ }^{9}$ The average UE and EU rate that we compute using the SIPP are below those computed by Shimer (2007) and Gorry (2011) using the CPS. Moreover, Gorry (2011) finds the age profile of the UE rate is declining throughout the entire lifecycle, while we find that the UE rate is approximately constant for workers between the age of 20 and 50. There are two reasons for these discrepancies. The first reason has to do with the data. Nagypal (2008) demonstrated, using CPS re-interview data, the presence of significant classification error in the CPS that misclassifies out-of-labor-force workers as unemployed; she shows that this error overstates the average UE rate, e.g., by 26\%. SIPP does not have this problem. Moreover, Nagypal (2008) points out the importance of mismatch (attrition) error in the CPS, which is also biased towards workers in their 20's. SIPP data appears to be free of this error. The second reason for the discrepancy between our transition rates and those reported by Shimer (2007) and Gorry (2011) has to do with the definition of these rates. Basically, Shimer (2007) and Gorry (2011) define the transition rates as the probability that a worker experiences that type of transition during a month. In contrast, we define the UE, EU and EE transition rates as the probability that a worker is in a given employment state at the beginning of the month and in a different employment state at the beginning of the next month. Clearly, our definition of transition implies lower rates than the one adopted by Shimer (2007) and Gorry (2011).
} 
Figure 7 displays the raw and smoothed age profiles of the monthly NL rate. Notice that the monthly NL rate is steadily decreasing with age. For example, the monthly NL rate is close to 12.5 percent for workers who are 20 years old, it drops off to 6 percent for workers who are 40 years old, and it is lower than 2 percent for workers who are 60 years old. Figure 8 displays the raw and smoothed age profiles of the monthly LN rate. The monthly LN rate is U-shaped over the life cycle. The monthly LN rate is above 4 percent for very young workers, it declines to about 1 percent for workers between the ages of 25 and 55, and it increases to 2.5 percent for workers older than 60 .

Our model can only account for some of the workers' transitions in and out of the labor force. In our model, workers enter the labor force for exogenous reasons (e.g. the end of their formal education), and they participate in the labor market until they permanently exit the labor force for exogenous reasons (e.g. a permanent illness or a permanent productivity decline). Hence, our model can account for the transition of young workers from school to the labor force and for the transition of old workers from the labor force into retirement (as long as one views retirement as the effect of an exogenous decline in productivity). However, our model does not allow participating workers to move out and back into the labor force. Hence, our model cannot account for middle-aged workers who temporarily move out of the labor force because of some temporary illness or because of discouragement.

In an attempt to minimize the discrepancy between the model and the data, we constructed a sample of the SIPP data from which we excluded workers who experience any transitions out and into the labor force between the ages of 25 and 50 . We found that there are not many such workers. That is, most of the transitions of prime-aged workers out and into the labor force are attributable to a small number of marginally attached workers. More importantly, we found that, in the restricted dataset, the age profiles of the UE, EU and EE rates, the age profile of wages and the tenure profiles of the EU and EE rates are very similar to those in the unrestricted dataset. This finding reassures us that leaving marginal workers in the dataset will not have a significant impact on our quantitative analysis. 


\subsection{Tenure profile of transitions within the labor force}

To calibrate the parameters of our model, we will make use of the empirical relationship between a worker's tenure on a job and the probability that the worker moves into a different job or into unemployment. Formally, we construct the tenure profile of the monthly EU and $\mathrm{EE}$ as follows. The EU rate for workers of tenure $t$ is defined as the number of employed workers with tenure $t$ who experience a EU transition in the subsequent month divided by the number of employed workers with tenure $t$. Similarly, the EE rate for workers of tenure $t$ is defined as the number of employed workers with tenure $t$ who experience an EE transition in the subsequent month divided by the number of employed workers with tenure $t$.

Figures 9 and 10 display the raw and smoothed tenure profiles of the monthly EU and EE rates. The tenure profile of the EU rate is decreasing and convex. The EU rate is close to 2 percent for workers who have been on the job for 3 months; it drops to 0.5 percent for workers with 24 months of tenure, and to 0.3 percent for workers with 48 months of tenure. The tenure profile of the monthly EE rate displays a similar pattern. For workers with 3 months of tenure, the EE rate is close to 4 percent. The EE rate drops off to 2 percent for workers with 24 months of tenure, and it declines at a much lower rate for workers with longer tenure. Notice that the shape of the tenure profile of the EU and EE rates that we constructed using the SIPP is very similar to the shape of the tenure profile that Topel and Ward (1992) construct using the NLSY.

\subsection{Age profile of wages}

To calibrate the parameters of our model, we will also make use of the empirical relationship between a worker's age and wage. Formally, we measure the wage of an employed worker as the logarithm of the monthly wage and salary income at the worker's dominant job. We then construct the age profile of wages by averaging our measure of wages across each age group. The resulting age profile in figure 11 has the usual concave shape, increasing quickly

early in the life cycle, then increasing at a much slower rate after the mid-30's. As expected, the population average wages are higher later in the life cycle than those of the high-school education group, but the shape of the profiles is similar. 


\section{Calibration, validation and application of the theory}

In this section, we first calibrate our model using aggregate data on labor reallocation, such as the unconditional mean of the UE, EU and EE rates and the mean of the EU and EE rates conditional on the worker's tenure on the job. Second, we validate our calibrated model by showing that it correctly predicts the mean of the UE, EU and EE rates conditional on the worker's age. Finally, we apply our calibrated model in order to decompose the effect of age on the UE, EU and EE rates into the effect of changes in work-life expectancy, changes in human capital and changes in match quality. Similarly, we use the calibrated model to decompose the growth of wages and productivity over the life cycle into the effect of human capital accumulation, match quality accumulation and improvements in the worker's contractual position.

\subsection{Calibration}

To begin the description of the strategy and outcome of the calibration, let us review the parameters that describe our model. Preferences are described by the discount factor, $\beta$, and the value of leisure $b$. The production process is described by the probability distribution of the quality of a match, $f(z)$, the probability that the quality of a match is observed, $\alpha$, the probability that the quality of a match changes, $\eta$, and the production function, $h(y)$. We restrict $f(z)$ to be a 100-point approximation of a Weibull distribution with mean 1, scale $\sigma$ and shape $\phi$. We also restrict $g(y)$ to be of the form $g(y)=(1-\zeta)+\zeta y^{\psi}$. The matching process is described by the vacancy cost, $k$, the probability that an unemployed worker gets to search, $\lambda_{u}$, the probability that an employed worker gets to search, $\lambda_{e}$, the probability that a worker becomes unemployed for exogenous reasons, $\delta$, and the matching probability $p(\theta)$, which we restrict to be of the form $p(\theta)=\min \left\{\theta^{1 / 2}, 1\right\} .{ }^{10}$ We set $\lambda_{u}$ to 1 , which is a normalization that pins down the unit of measure for vacancies. Finally, the process of entry and exit into the labor market is described by the probabilities $\left\{\mu_{t}, \nu_{t}\right\}$.

\footnotetext{
${ }^{10}$ Typically, the elasticity of the job finding probability function $p$ with respect to $\theta$ is estimated using data on the cyclical fluctuations of the UE rate and of the aggregate labor market tightness (see, e.g., Shimer 2005 and Menzio and Shi 2011). Since our model abstracts from cyclical fluctuations, we did not attempt to estimate the elasticity of $p$. Instead, we chose an elasticity of .5, which is close to the value estimated by Menzio and Shi (2011) using a model of directed search on the job that is similar to ours. Moreover, as a robustness check, we carried out the quantitative analysis of the model using two alternative values for the elasticity of $p$ (0.3 and 0.7$)$ and found no significant differences with respect to the benchmark case.
} 
Next, let us describe how we calibrate the parameters of the model. We set the model period to be one month. We calibrate $\beta$ so that the annual real interest rate in the model, $\beta^{-12}$, is equal to 4 percent. We calibrate $\mu_{t}$ so that the fraction of workers of age $t$ who enter the labor market is the same in the model as in the data. Similarly, we calibrate $\nu_{t}$ so that the fraction of workers of age $t$ who retire from the labor market is the same in the model as in the data. The remaining parameters are calibrated so as to minimize the distance between the value of some statistical moments in the data and in the model. In particular, the statistical moments that we consider are the average UE, EU and EE rates, the average EU and EE rates for workers with different tenure, the average wage for workers with different age, and the average wage-to-leisure ratio. Heuristically, the average UE, EU and EE rates are used to calibrate the search parameters $k, \delta$ and $\lambda_{e}$. The tenure profile of the EU and EE rate is used to calibrate the production parameters $\alpha, \eta, \sigma$ and $\phi{ }^{11}$ The age profile of wages is used to calibrate the human-capital parameters $\zeta$ and $\psi$. Finally, the ratio of wages to home production — which Hall and Milgrom (2008) estimate to be 0.7-is used to calibrate the parameter $b$.

Most of our calibration strategy is standard (see, e.g., Shimer 2005). The main novelty is to use the empirical tenure profile of the EU and EE rates to calibrate the probability distribution of match quality, $f(z)$, and the parameters $\alpha$ and $\eta \cdot{ }^{12}$ Let us briefly explain why the tenure profiles of the EU and EE rates are related to $f(z), \alpha$ and $\eta$. In our model, when a firm and a worker do not know the quality of their match, the probability that - over the next month - the worker moves into unemployment is $\delta$ and the probability that he moves into another job is zero. When a firm and a worker know the quality of their match, the probability that - over the next month - the worker moves into unemployment is $d_{t}(z, y)$ and the probability that he moves into another job is $\left(1-d_{t}(z, y)\right) \lambda_{e} p\left(\theta_{t}^{e}(z, y)\right)$, where $d_{t}(z, y)$ and $p\left(\theta_{t}^{e}(z, y)\right)$ are decreasing in $z$. Therefore, the probability distribution of match quality, $f(z)$, the rate at which match quality is observed, $\alpha$, and the rate at which match quality changes, $\eta$, affect the number of matches that reach a particular tenure and the fraction of

\footnotetext{
${ }^{11}$ Notice that targeting the tenure profiles of the EU and EE rates does not automatically predispose the model to match the age profiles of the EU and EE rates, because the tenure profile need not be the same for workers of different ages.

${ }^{12}$ Moscarini (2003) uses the tenure profile of the exit-hazard rate to calibrate the rate at which a firm and a worker learn about the quality of their match. Similarly, Menzio and Shi (2011) use the tenure profile of the exit-hazard rate to calibrate the match-quality distribution. In this paper, we use both the tenure profile of the EU hazard and the tenure profile of the EE hazard to calibrate the parameters of the model.
} 
these matches that terminate because the workers move into unemployment or into another job. Conversely, the empirical tenure profile of the $\mathrm{EU}$ and $\mathrm{EE}$ rates is informative about $\alpha$, $\eta$ and $f(z)$.

Finally, we turn to the outcomes of the calibration. Table 1 reports the calibrated values of the model parameters. Tables 2, 3 and 4 report the values of the target moments in the data and in the model. The calibrated values of the search parameters $k, \delta$ and $\lambda_{e}$ are, respectively, 23, .002 and .66. The calibrated value of $k$ implies that the expected cost of hiring an unemployed worker of age 40 with 15 years of experience is equal to 1.8 months of the worker's expected output. The calibrated value of $\delta$ implies that only 1 out of 3 transitions from employment to unemployment are exogenous. The calibrated value of $\lambda_{e}$ implies that the main reason why unemployed workers have a much higher job finding rate than employed workers is that unemployed workers choose to search for jobs that offer lower wages, not that unemployed workers are more likely to search. Given the calibrated values of the search parameters, the average UE, EU and EE rates generated by the model are fairly close to their empirical counterparts.

The calibrated values of $\sigma$ and $\phi$ are, respectively, 11.2 and 3.6. These parameter values imply that there is a great deal of uncertainty about the quality of a new match. For example, the productivity of a match in the 90th percentile of the distribution $f(z)$ is approximately 3 times higher than the productivity of a match in the 10th percentile of the distribution. The calibrated value of $\alpha$ is .26, which implies that it does not take long to learn the quality of a match. In particular, it implies that more than 70 percent of firms and workers learn the quality of their match during the first four months of their union. The calibrated value of $\eta$ is .0094, which implies that the quality of a match is very persistent. In particular, it implies that, on average, the quality of a match changes once every 8 and a half years. Given the calibrated value of these technology parameters, the model reproduces quite closely the tenure profiles of the EU and EE rates that are observed in the data (see Table 3).

The calibrated values of $\zeta$ and $\psi$ are, respectively, 4.43 and .011. These values imply that the effect of an additional year of experience on a worker's productivity falls dramatically with the worker's level of experience. For instance, the productivity of the worker approximately doubles with the first 2.5 years of experience, and only increases by 45 percent with the next 
5 years of experience. Given the calibrated valued for $\zeta$ and $\psi$, the model reproduces quite closely the age profile of average wages (see Table 4).

The calibration reveals that there is a great deal of heterogeneity in the quality of firmworker formed matches. The search frictions that slow down the process of assignment of the right workers to the right firms are modest, in the sense that workers are almost always able to search the labor market and that firms pay a relatively small cost to open new vacancies. Similarly, the learning frictions are modest, in the sense that firms and workers learn rather quickly the quality of their match. Overall, the large heterogeneity in match quality and the modest search and learning frictions add up to a fairly time consuming process of selection of the right workers into the right firms.

\subsection{Validation}

In order to validate our model, we use data on labor reallocation disaggregated according to the workers' age. In particular, we show that the calibrated model correctly predicts the average of the EE, EU and UE transition rates conditional on the workers' age.

\subsubsection{Lifecycle profile of the EE rate}

The age profile of the EE rate predicted by the model is close to the age profile of the EE rate that is observed in the data (see Figure 12). Specifically, the model correctly predicts that the EE rate is decreasing throughout the life cycle and it correctly predicts the speed at which it declines. For example, the model correctly predicts that the EE rate drops rapidly for workers between the ages of 20 and 35, that it remains approximately constant for workers between the ages of 35 and 50, and that it declines for older workers. The close proximity between the age profile predicted by the model and the one observed in the data should also be considered a success of the theory. In calibrating the parameters of the model we used the tenure profile of the EE rate, which, obviously, is related to the age profile of the EE

rate. However, since the tenure profile of the EE rate need not be constant for workers of different age (and, in fact, it is not) and the fraction of workers starting new jobs at different ages is used in the calibration, our model is not "rigged" to fit the age profile of the EE rate. 
Now, we can use the model to decompose the age variation of the EE rate into the contribution of the three workers' characteristics that vary with age: life-expectancy, match quality and experience. To this aim, let us decompose the difference between the EE rate for workers of age $t, h_{t}^{e e}$, and the EE rate for workers of age $t-1, h_{t-1}^{e e}$, as follows

$$
\begin{aligned}
& h_{t}^{e e}-h_{t-1}^{e e} \\
= & \int_{z}\left[\int_{y} p_{t}^{e}(z, y) \Phi_{t}^{e}(y \mid z) d y\right] \Omega_{t}^{e}(z) d z-\int_{z}\left[\int_{y} p_{t-1}^{e}(z, y) \Phi_{t}^{e}(y \mid z) d y\right] \Omega_{t}^{e}(z) d z \\
+ & \int_{z}\left[\int_{y} p_{t-1}^{e}(z, y) \Phi_{t}^{e}(y \mid z) d y\right] \Omega_{t}^{e}(z) d z-\int_{z}\left[\int_{y} p_{t-1}^{e}(z, y) \Phi_{t}^{e}(y \mid z) d y\right] \Omega_{t-1}^{e}(z) d z \\
+ & \int_{z}\left[\int_{y} p_{t-1}^{e}(z, y) \Phi_{t}^{e}(y \mid z) d y\right] \Omega_{t-1}^{e}(z) d z-\int_{z}\left[\int_{y} p_{t-1}^{e}(z, y) \Phi_{t-1}^{e}(y \mid z) d y\right] \Omega_{t-1}^{e}(z) d z
\end{aligned}
$$

where $\Omega_{t}^{e}(z)$ is the distribution of employed workers of age $t$ across $z, \Phi_{t}^{e}(y \mid z)$ is the distribution of employed workers of age $t$ across $y$ conditional on $z$, and $p_{t}^{e}(z, y)$ is the probability that a worker $(t, y)$ in a match of quality $z$ experiences a job-to-job transition, i.e. $p_{t}^{e}(z, y)=\left[1-d_{t}(z, y)\right] \lambda_{e} p\left(\theta_{t}^{e}(z, y)\right)$. The first term on the right-hand side of $(12)$ is the difference between the actual EE rate for workers of age $t$ and the counterfactual EE rate for workers of age $t-1$ if these workers had the same experience and match quality as workers of age $t$. Following Chéron, Hairault and Langot (2007), we shall refer to this term as the horizon effect of age. The second term on the right-hand side of (12) is the difference between the EE rate for workers of age $t-1$ who counterfactually have the same experience and match quality as workers of age $t$ and the EE rate for workers of age $t-1$ who counterfactually have the same experience as workers of age $t$. We shall refer to this term as the selection effect of age. Finally, the last term on the right-hand side of (12) is the difference between the EE rate for workers of age $t-1$ who have the same experience as workers of age $t$ and the actual EE rate for workers of age $t-1$. We shall refer to this term as the experience effect of age.

Figure 13 plots the decomposition of $h_{t}^{e e}-h_{t-1}^{e e}$ into the horizon, selection and experience effects. The horizon effect is negative because - as we discussed in section 3.4 -workers with a shorter work-life expectancy choose to search in submarkets where the vacancy to applicant ratio is lower (as long as the quality of their current job is not too high). Quantitatively, the horizon effect is negligible until the age of 50 because a worker with more than 15 years of 
remaining work life behaves approximately like a worker with an infinite work life. Past the age of 50, the horizon effect becomes stronger and stronger. The selection effect is negative because workers of age $t$ are selected into matches of higher quality than workers of age $t-1$ and - as we discussed in section 3.4-workers in higher quality matches choose to search in submarkets where the vacancy to applicant ratio is lower. ${ }^{13}$ Quantitatively, the selection effect is small after the age of 30 because workers who have been in the labor market for more than 10 years have found high quality matches. Before the age of 30, the selection effect is quite strong. Finally, the experience effect is positive because workers of age $t$ have accumulated more experience than workers of age $t-1$ and - as we discussed in section 3.4workers with more experience choose to search in submarkets where the vacancy to applicant ratio is higher (as long as the quality of their current job is not too high). Quantitatively, though, the experience effect is quite small.

Figure 13 shows that the large decline in the EE rate for workers between the ages of 20 and 35 is almost entirely attributable to the selection effect of age, i.e. to the fact that workers move from low to high quality matches as they get older. Figure 13 also shows that the EE rate for workers between the ages of 35 and 45 is approximately constant because, in this part of the life cycle, the horizon, selection and experience effects of age are all negligible. Finally, Figure 13 shows that the decline in the EE rate for workers between the ages of 45 and 65 is almost entirely attributable to the horizon effect of age, i.e. to the fact that workers' work-life expectancy falls as they get older.

\subsubsection{Lifecycle profile of the EU rate}

The age profile of the EU rate predicted by the model is qualitatively close to the age profile of the EU rate that is observed in the data (see Figure 14). In particular, the model correctly predicts that the EU rate drops dramatically for workers between the ages of 18 and 30 and that it declines at a much smaller rate for older workers. The close fit between the age profile predicted by the model and the one observed in the data should also be considered a success

\footnotetext{
${ }^{13}$ Between the ages of 18 and 19, the selection effect is actually positive. This is because most 18 year old workers who are employed are in matches of unknown quality and, hence, do not have an incentive to search for better matches. The proportion of 19 year old employed workers who are in matches of unknown quality is much lower and, for this reason, the selection effect is positive. After the first year, the main difference between older and younger worker is that the older ones are employed in better matches.
} 
for our theory of labor reallocation. In fact, even though we used the tenure profile of the EU rate in the calibration, our model is not necessarily predisposed to fit the age profile of the EU rate because the tenure profile of the EU rate need not be the same for workers of different age.

In order to understand the cause of age variation in the EU rate, we decompose the difference between the EU rate for workers of age $t, h_{t}^{e u}$, and the EU rate for workers of age $t-1, h_{t-1}^{e u}$, as follows

$$
\begin{aligned}
& h_{t}^{e u}-h_{t-1}^{e u} \\
= & \int_{z}\left[\int_{y} d_{t}(z, y) \Phi_{t}^{e}(y \mid z) d y\right] \Omega_{t}^{e}(z) d z-\int_{z}\left[\int_{y} d_{t-1}(z, y) \Phi_{t}^{e}(y \mid z) d y\right] \Omega_{t}^{e}(z) d z \\
+ & \int_{z}\left[\int_{y} d_{t-1}(z, y) \Phi_{t}^{e}(y \mid z) d y\right] \Omega_{t}^{e}(z) d z-\int_{z}\left[\int_{y} d_{t-1}(z, y) \Phi_{t}^{e}(y \mid z) d y\right] \Omega_{t-1}^{e}(z) d z \\
+ & \int_{z}\left[\int_{y} d_{t-1}(z, y) \Phi_{t}^{e}(y \mid z) d y\right] \Omega_{t-1}^{e}(z) d z-\int_{z}\left[\int_{y} d_{t-1}(z, y) \Phi_{t-1}^{e}(y \mid z) d y\right] \Omega_{t-1}^{e}(z) d z
\end{aligned}
$$

The decomposition in (13) is the analogue for the EU rate of the decomposition in (12). The first term on the right-hand side of (13) measures the contribution of the change in work-life expectancy to the change in the EU rate between workers of age $t-1$ and $t$. This is the horizon effect of age. The second term on the right-hand side of (13) measures the contribution of the change in match quality to the change in the EU rate between workers of age $t-1$ and $t$. This is the selection effect of age. Finally, the last term on the right-hand side of (13) measures the contribution of the change in experience to the change in the EU rate between workers of age $t-1$ and $t$. This is the experience effect of age.

Figure 15 plots the decomposition of $h_{t}^{e u}-h_{t-1}^{e u}$ into the selection, experience and horizon effects. The horizon effect is negative because workers with a shorter work-life expectancy are more likely to leave their job as they have less to gain from accumulating an additional month of experience. Quantitatively, though, the horizon effect is rather small. The selection effect is negative because workers of age $t$ tend to be employed in higher quality matches than workers of age $t-1$ and, hence, they are less likely to leave their job. Quantitatively, the selection effect is quite strong between the ages of 18 and 30, but it becomes negligible afterwards. Finally, the experience effect is positive early in the life cycle and negative later on. In fact, workers of age $t$ have more experience than workers of age $t-1$ and, as 
illustrated in figure 6, workers with more experience are more likely to leave their job if young and less likely to leave their job if old. Notice that the magnitude of the experience effect sharply declines with age because, according to our calibration, the marginal productivity of experience falls rather quickly.

Figure 15 shows that the sharp decline in the EU rate for workers between the ages of 18 and 30 is attributable to the fact that, during this part of the life cycle, the negative effect of age on the EU rate through the selection channel is much stronger than its positive effect through the experience channel. Moreover, Figure 15 shows that the small decline in the EU rate for workers between the ages of 30 and 65 is due to the fact that, during this part of the life cycle, the horizon, selection and experience effects of age are all rather small.

\subsubsection{Lifecycle profile of the UE rate}

Figure 16 shows that the model also predicts quite well the empirical age profile of the UE rate. In particular, the model correctly predicts that the UE rate remains approximately constant for workers between the ages of 20 and 50 and that the UE rate sharply declines for workers between the ages of 50 and 65 . Since the calibration did not use any data on the age variation of the UE rate, the fact that the model correctly predicts the empirical age profile of the UE rate should be seen as another success of our theory.

In order to understand the causes of the age variation in the UE rate, we decompose the difference between the UE rate for workers of age $t, h_{t}^{u e}$, and the UE rate for workers of age $t-1, h_{t-1}^{u e}$, as follows

$$
\begin{aligned}
h_{t}^{u e}-h_{t-1}^{u e} & =\int_{y} p\left(\theta_{t}^{u}(y)\right) \Phi_{t}^{u}(y) d y-\int_{y} p\left(\theta_{t-1}^{u}(y)\right) \Phi_{t}^{u}(y) d y \\
& +\int_{y} p\left(\theta_{t-1}^{u}(y)\right) \Phi_{t}^{u}(y) d y-\int_{y} p\left(\theta_{t-1}^{u}(y)\right) \Phi_{t-1}^{u}(y) d y,
\end{aligned}
$$

where $\Phi_{t}^{u}(y)$ is the distribution of unemployed workers of age $t$ across $y$. The decomposition in (14) is similar to the decomposition in (12) and (13) for the EE and EU rates. The first term on the right-hand side of (14) measures the contribution of the change in worklife expectancy to the change in the UE rate between workers of age $t-1$ and $t$. This is the horizon effect of age. The second term on the right-hand side of (14) measures the contribution of the change in experience to the change in the UE rate between workers of 
age $t-1$ and $t$. This is the experience effect of age. Clearly, age does not affect the UE rate through its effect on the selection of workers into higher quality matches.

Figure 17 plots the decomposition of $h_{t}^{u e}-h_{t-1}^{u e}$ into the horizon effect and the experience effect. The horizon effect is negative because - as illustrated in figure 4-unemployed workers with a shorter work-life expectancy choose to search in submarkets where the vacancy to applicant ratio, and, hence, their job finding probability is lower. The experience effect is positive because workers of age $t$ have more experience than workers of age $t-1$ and - as figure 4 shows - more experienced workers choose to search in submarkets where the vacancy to applicant ratio and, hence, their job finding probability is higher. Overall, figure 17 shows that the UE rate is approximately constant for workers between the ages of 20 and 50 because both the horizon and experience effects are negligible. Moreover, the UE rate declines sharply for workers between the ages of 50 and 65 because the horizon effect becomes strong, while the experience effect remains relatively small.

\subsection{Application: Decomposing productivity and wage growth}

In the previous subsections, we used the model to decompose the age variation in the UE, EU and EE transition rates into the contribution of the age variation in work-life expectancy, match quality and experience. Those decompositions shed light on the fundamental causes of age variation in labor reallocation. In this subsection, we want to use the model to decompose the age profile of labor productivity and wages.

First, let $\zeta$ denote the productivity of an employed worker. Using the fact that $\zeta=z g(y)$, we can decompose the growth rate of average labor productivity between the ages of $t-1$ and $t$ as follows

$$
\begin{aligned}
{\left[\mathbb{E}_{t} \log \zeta-\mathbb{E}_{t-1} \log \zeta\right] } & =\left[\mathbb{E}_{t} \log g(y)-\mathbb{E}_{t-1} \log g(y)\right] \\
& +\left[\mathbb{E}_{t} \log z-\mathbb{E}_{t-1} \log z\right]
\end{aligned}
$$

where $\mathbb{E}_{t} x$ denotes the average value of some variable $x$ among workers of age $t$ and $\mathbb{E}_{t-1} x$ denotes the average among workers of age $t-1$. The first term on the right-hand side of (15) measures the growth rate between the ages of $t-1$ and $t$ of the average human capital of employed workers. The second term is the growth rate between the ages of $t-1$ and $t$ of average match quality of employed workers. Hence, (15) decomposes the growth rate of 
labor productivity into the contributions of the growth rates of human capital and of match quality.

Next, denote as $\omega$ the piece-rate for an employed worker and as $w$ his wage. Using the fact that $w=\omega z g(y)$, we can decompose the growth rate of the average wage between the ages of $t-1$ and $t$ as follows

$$
\begin{aligned}
{\left[\mathbb{E}_{t} \log \zeta-\mathbb{E}_{t-1} \log \zeta\right] } & =\left[\mathbb{E}_{t} \log g(y)-\mathbb{E}_{t-1} \log g(y)\right] \\
& +\left[\mathbb{E}_{t} \log z-\mathbb{E}_{t-1} \log z\right]+\left[\mathbb{E}_{t} \log \omega-\mathbb{E}_{t-1} \log \omega\right],
\end{aligned}
$$

The sum of the first two terms on the right-hand side of (16) is the growth rate of average labor productivity among employed workers. The last term on the right-hand side of (16) is the growth rate of the average piece rate among employed workers. Hence, (16) decomposes the growth rate of wages into the contribution of the growth rates of human capital, match quality and worker's contractual power.

Figure 18 plots the decomposition of the growth rate of labor productivity into the contribution of the growth rate of human capital and of match quality. First, notice that labor productivity growth decreases rapidly with age. Between the ages of 18 and 22, labor productivity grows by 18 percent per year. Between the ages of 23 and 27, labor productivity grows by 5.4 percent per year. And between the ages of 28 and 65 , average productivity grows only by .6 percent per year. Second, notice that both the accumulation of human capital and the increase in match quality are both important sources of labor productivity growth. In particular, between the ages of 18 and 30, the accumulation of human capital accounts for 74 percent, and the increase of match quality accounts for 25 percent of the overall growth of labor productivity. Finally, Figure 18 shows very clearly that the assignment of the right workers to the right firms is a process that lasts approximately 10 years, even though both search and learning frictions are modest.

Figure 19 plots the decomposition of the growth rate of wages into the contribution of the growth rate of human capital, match quality and workers' contractual power. First, notice that average wages - just like labor productivity - are increasing in age, but at a rapidly decreasing rate. The annual growth rate of wages is 18 percent between the ages of 18 and 22, 5.5 percent between the ages of 23 and 27, and .6 percent between the ages of 28 and 65 . Second, notice that the main engines of wage growth are the accumulation of human capital 
and the improvement in match quality, not the increase in workers' contractual power. In fact, between the ages of 18 and 30, the growth of human capital accounts for 76 percent of wage growth, the improvement in match quality accounts for 23.8 percent of wage growth, and the increase in workers' contractual power only accounts for 0.2 percent of wage growth. The workers' contractual power contributes very little to wage growth because, according to our calibration, search frictions are small and, hence, workers are always paid wages close to their marginal product.

The findings obtained from the decompositions (15) and (16) reveal the importance of mismatch in the growth process of productivity and wages over the life cycle. Indeed, more that 20 percent of the productivity and wage growth that workers experience during their entire life cycle reflects the workers' movement towards a more efficient allocation of their labor and towards a stronger contractual position. These findings have far-reaching implications. For example, they suggest that labor market policies that hinder workers' mobility (e.g. firing costs) have the potential to dramatically slow down the workers' productivity and wage growth over the life cycle. Similarly, such policies may significantly reduce the aggregate level of labor productivity.

\section{Conclusions}

In this paper, we developed a directed search theory of workers' transitions between employment, unemployment and across employers over the life cycle. The transitions of workers across different employment states are driven by differences in the quality of different firmworker matches. The assignment of the right workers to the right firms is time consuming because of the presence of both search and learning frictions. The velocity at which workers move towards new firms is endogenous because search is directed and, hence, workers choose whether to seek jobs that offer high wages and are hard to find or jobs that offer low wages and are easy to find. We calibrated the theory using data on labor reallocation aggregated across workers of different ages. We validated the theory by showing that it correctly predicts the empirical pattern of labor reallocation for workers of different ages. Finally, we used the theory to decompose the age variation of transition rates, wages and productivity into the effect of age variations in work-life expectancy, human capital and match quality. 
The model proposed in this paper provides a successful and practical way to introduce life cycle considerations into macroeconomic analysis of the labor market. The model is successful because it accounts for the pattern of workers' transitions across employment states over the life cycle. The model is practical because, due to the block recursivity of the equilibrium, it can be easily solved in the presence of aggregate shocks. For example, it would be interesting to introduce cyclical fluctuations in aggregate productivity into the framework and measure their effect on the unemployment rate, transition rates and match quality of workers of different ages. This type of analysis would reveal which age groups are most sensitive to cyclical productivity fluctuations and whether it is innocuous to abstract from age heterogeneity when studying the cyclical volatility of aggregate unemployment and vacancies. Similarly, it would be interesting to measure the effect of changes in demographic structure on aggregate unemployment, vacancies and reallocation, as well as on the growth rate of wages and labor productivity. This type of analysis would reveal how much of the recent slow-down in the growth rate of wages and labor productivity can be attributed to the ageing of the baby boomers. 


\section{References}

[1] Albrecht, J., P. Gautier and S. Vroman. 2006. "Equilibrium directed search with multiple applications". Review of Economic Studies 73: 869-91.

[2] Bagger, J., F. Fontaine, F. Postel-Vinay and J. Robin. 2007. "A Tractable Equilibrium Search Model with Experience Accumulation". Manuscript, Bristol University.

[3] Burdett, K., and D. Mortensen. 1998. "Wage Differentials, Employer Size, and Unemployment." International Economic Review 39: 257-73.

[4] Burdett, K., S. Shi, and R. Wright. 2001. "Pricing and Matching with Frictions." Journal of Political Economy 109: 1060-85.

[5] Burdett, K., C. Carillo-Tudela and M. Coles. 2011. "Human Capital Accumulation and Labor Market Equilibrium”. Forthcoming, International Economic Review 42: 597-616.

[6] Burdett, K. and M. Coles. 2010. "Equilibrium Contracts with On-the-Job Learning and Search". Manuscript, University of Pennsylvania.

[7] Chéron, A., J.-O. Hairault, and F. Langot. 2008. "Life-Cycle Equilibrium Unemployment". IZA Discussion Papers 3396.

[8] Chéron, A., J.-O. Hairault, and F. Langot. 2011. "Age-Dependent Employment Protection". Economic Journal 121: 1477-504.

[9] Eeckhout, J., and P. Kircher. 2010. "Sorting and Decentralized Price Competition." Econometrica 78: 539-74.

[10] Esteban-Pretel, J., and J. Fujimoto. 2011. "Life-Cycle Labor Search with Stochastic Match Quality", Manuscript. GRIPS.

[11] Fu, C. 2011. "Training, Search and Wage Dynamics". Review of Economic Dynamics 14: $650-66$.

[12] Galenianos, M., and P. Kircher. 2009. "Directed Search with Multiple Job Applications." Journal of Economic Theory 144: 445-71. 
[13] Gorry, A. 2011. "Experience and Worker Flows". Manuscript, University of California at Santa Cruz.

[14] Hall, R., and P. Milgrom. 2008. "The Limited Influence of Unemployment of the Wage Bargain." American Economic Review 98: 1653-74.

[15] Menzio, G. and S. Shi. 2010a. "Block Recursive Equilibria for Stochastic Models of Search on the Job." Journal of Economic Theory. 145: 1453-94.

[16] Menzio, G. and S. Shi. 2010b. "Directed Search on the Job, Heterogeneity, and Aggregate Fluctuations." American Economic Review 100: 327-32.

[17] Menzio, G. and S. Shi. 2011. "Efficient Search on the Job and the Business Cycle." Journal of Political Economy 119: 468-510.

[18] Moen, E. 1997. "Competitive Search Equilibrium." Journal of Political Economy 105: 694-723.

[19] Montgomery, J. 1991. Equilibrium Wage Dispersion and Interindustry Wage Differentials. Quarterly Journal of Economics 106: 163-79.

[20] Mortensen, D., and C. Pissarides. 1994. "Job Creation and Job Destruction in the Theory of Unemployment." Review Economic Studies 61: 397-415.

[21] Moscarini, G. 2003. "Skill and Luck in the Theory of Turnover." Manuscript, Yale University.

[22] Nagypal, E. 2008. "Worker Reallocation over the Business Cycle: The Importance of Employer to Employer Transitions". Manuscript, Northwestern University.

[23] Pissarides, C. 1985. "Short-Run Equilibrium Dynamics of Unemployment, Vacancies and Real Wages." American Economic Review 75: 676-90.

[24] Postel-Vinay F., and J. Robin. 2001. "The Distribution of Earnings in an Equilibrium Search Model with State-Dependent Offers and Counter-Offers." International Economic Review 43: 989-1016. 
[25] Postel-Vinay F., and J. Robin. 2002. "Equilibrium Wage Dispersion with Worker and Employer Heterogeneity." Econometrica 70: 2295-350.

[26] Postel-Vinay, F. and H. Turon. 2010. "On-the-job Search, Productivity Shocks, and the Individual Earnings Process", International Economic Review, 51: 599-629.

[27] Topel, R. and M. Ward. 1992. "Job Mobility and the Careers of Young Men", Quarterly Journal of Economics, 107: 439-79.

[28] Shi, S. 2009. "Directed Search for Equilibrium Wage-Tenure Contracts." Econometrica, 77: $561-584$.

[29] Shimer, R. 1996. "Contracts in a Frictional Labor Market." Manuscript, M.I.T.

[30] Shimer, R. 2005. "The Cyclical Behavior of Unemployment and Vacancies." American Economic Review 95: 25-49.

[31] Shimer, R. 2007. "Reassessing the Ins and Outs of Unemployment". Manuscript, University of Chicago.

[32] Van den Berg, G., and G. Ridder. 1998. "An Empirical Equilibrium Search Model of the Labor Market." 66: 1183-221.

[33] Zhao, M., and M. Faig. "Labor Market Cycles, Unemployment Insurance Eligibility, and Moral Hazard." Review of Economic Dynamics 15: 41-56. 


\section{Appendix}

Proof of Theorem 1: The unemployment value function $U_{T}$ and the employment value function $V_{T}$ satisfy the equilibrium conditions (iii) and (iv) if and only if

$$
\begin{aligned}
U_{T}(y, \psi) & =b \\
V_{T}(z, y, \psi) & = \begin{cases}z g(y), & \text { if } z=z_{1}, z_{2}, \ldots z_{N(z)}, \\
\sum_{z^{\prime}} z^{\prime} g(y) f\left(z^{\prime}\right), & \text { if } z=z_{0} .\end{cases}
\end{aligned}
$$

Notice that neither $U_{T}$ nor $V_{T}$ depend on the aggregate state of the economy $\psi$. Hence, we can write $U_{T}(y, \psi)=U(y)$ and $V_{T}(z, y, \psi)=V_{T}(z, y)$.

The market tightness function $\theta_{T}$ satisfies the equilibrium condition (ii) if and only if

$$
\theta_{T}(x, y, \psi)= \begin{cases}q^{-1}\left(\frac{k}{V_{T}\left(z_{0}, y\right)-x}\right), & \text { if } x \leq V_{T}\left(z_{0}, y\right)-k \\ 0, & \text { else. }\end{cases}
$$

Notice that $\theta_{T}(x, y, \psi)$ depends on the value promised to the workers, $x$, the worker-specific productivity, $y$, but not on the aggregate state of the economy, $\psi$. Hence, we can write $\theta_{T}(x, y, \psi)=\theta_{T}(x, y)$.

The unemployment policy function $x_{T}^{u}$ satisfies the equilibrium condition (iii) if and only if it solves the search problem

$$
R_{T}(y, \psi)=\max _{x} p\left(\theta_{T}(x, y)\right)\left[x-U_{T}(y)\right] .
$$

From (A2), it follows that $x=V_{T}\left(z_{0}, y\right)-k / q\left(\theta_{T}(x, y)\right)$ for all $x \leq V_{T}\left(z_{0}, y\right)-k$, and $\theta_{T}(x, y)=0$ for all $x>V_{T}\left(z_{0}, y\right)-k$. Using these equalities, we can rewrite the search problem (A3) as

$$
R_{T}(y, \psi)=\max _{x}-k \theta_{T}(x, y)+p\left(\theta_{T}(x, y)\right)\left[V_{T}\left(z_{0}, y\right)-U_{T}(y)\right] .
$$

Since $x$ enters (A4) only through $\theta_{T}$, we can rewrite the problem as

$$
R_{T}(y, \psi)=\max _{\theta \geq 0}-k \theta+p(\theta)\left[V_{T}\left(z_{0}, y\right)-U_{T}(y)\right]
$$

The objective function in (A5) is strictly concave in $\theta$ and does not depend on the aggregate 
state of the economy, $\psi$. Hence, (A5) admits a unique solution $\theta_{T}^{u}$ which does not depend on $\psi$, i.e. $\theta_{T}^{u}(y, \psi)=\theta_{T}^{u}(y)$. Similarly, $R_{T}(y, \psi)=R_{T}(y)$. Given $\theta_{T}^{u}, x_{T}^{u}$ must be such that

$$
\begin{array}{ll}
x_{T}^{u}(y, \psi)=V_{T}\left(z_{0}, y\right)-\frac{k}{q\left(\theta_{T}^{u}(y)\right)}, & \text { if } \theta_{T}^{u}(y)>0, \\
x_{T}^{u}(y, \psi) \geq V_{T}\left(z_{0}, y\right)-k, & \text { if } \theta_{T}^{u}(y)=0 .
\end{array}
$$

There are many policy function $x_{T}^{u}$ that solve (A6). However, the only difference between these policies is the $x$ that the worker chooses when he finds it optimal to visit an empty submarket. Hence, without loss in generality, we can specialize (A7) to

$$
x_{T}^{u}(y, \psi)=V_{T}\left(z_{0}, y\right)-\frac{k}{q\left(\theta_{T}^{u}(y)\right)} .
$$

Notice that $x_{u}^{T}$ does not depend on the aggegate state of the economy $\psi$. Hence, we can write $x_{T}^{u}(y, \psi)=x_{T}^{u}(y)$.

The employment policy function $x_{T}^{e}$ satisfies the equilibrium condition (iv) if and only if it solves the search problem

$$
S_{T}(z, y, \psi)=\max _{x} p\left(\theta_{T}(x, y)\right)\left[x-\mathbb{E}_{\hat{z} \mid z} V_{T}(\hat{z}, y)\right]
$$

Using (A2), we can rewrite the search problem (A8) as

$$
S_{T}(z, y, \psi)=\max _{\theta \geq 0}-k \theta+p(\theta)\left[V_{T}\left(z_{0}, y\right)-\mathbb{E}_{\hat{z} \mid z} V_{T}(\hat{z}, y)\right]
$$

The objective function in (A9) is strictly concave in $\theta$, it depends on the worker-specific productivity $y$ and on the match-specific productivity $z$ but not on the aggregate state of the economy, $\psi$. Hence, (A9) admits a unique solution $\theta_{T}^{e}$ which depends on $y$ and $z$ but not on $\psi$, i.e. $\theta_{T}^{e}(z, y, \psi)=\theta_{T}^{e}(z, y)$. Similarly, $S_{T}(z, y, \psi)=S_{T}(z, y)$. Given $\theta_{T}^{e}$, we can recover $x_{T}^{e}$ from

$$
x_{T}^{e}(z, y, \psi)=V_{T}\left(z_{0}, y\right)-\frac{k}{q\left(\theta_{T}^{e}(z, y)\right)} .
$$

Again, note that $x_{e}^{T}$ depends on the worker-specific productivity, $y$, the match-specific productivity, $z$, but not on the aggregate state of the economy, $\psi$. Hence, we can write $x_{T}^{e}(z, y, \psi)=x_{T}^{e}(z, y)$.

The employment policy function $d_{T}$ satisfies the equilibrium condition (iv) if and only if it 
solves the separation problem

$$
\max _{d \in[\delta, 1]} d U_{T}(y)+(1-d)\left[\mathbb{E}_{\hat{z} \mid z} V_{T}(\hat{z}, y)+\lambda_{e} S_{T}(z, y)\right]
$$

The objective function in (A11) is linear in $d$, it depends on the worker-specific productivity, $y$, and on the match-specific productivity, $z$, but not on the aggregate state of the economy, $\psi$. Hence, (A11) admits generally a unique solution $d_{T}$ which depends on $y$ and $z$ but not on $\psi$, i.e. $d_{T}(z, y, \psi)=d_{T}(z, y)$.

The unemployment value function $U_{T-1}$ satisfies the equilibrium condition (iii) if and only if

$$
U_{T-1}(y, \psi)=b+\beta\left[U_{T}(y)+\lambda_{u} R_{T}(y)\right]
$$

Similarly, the employment value function $V_{T-1}$ satisfies the equilibrium condition (iv) if and only if for $z=z_{1}, z_{2}, \ldots z_{N(z)}$ we have

$$
V_{T-1}(z, y, \psi)=z g(y)+\beta \max _{d \in[\delta, 1]}\left\{d U_{T}(\hat{y})+(1-d)\left[\mathbb{E}_{\hat{z} \mid z} V_{T}(\hat{z}, \hat{y})+\lambda_{e} S_{T}(z, \hat{y})\right]\right\}
$$

and for $z=z_{0}$ we have

$$
\begin{aligned}
& V_{t}\left(z_{0}, y, \psi\right)=\alpha \sum_{z} V_{T-1}(z, y) f(z)+(1-\alpha) \sum_{z} z g(y) f(z) \\
& \quad+(1-\alpha) \beta \max _{d \in[\delta, 1]}\left\{d U_{T}(\hat{y})+(1-d)\left[\mathbb{E}_{\hat{z} \mid z_{0}} V_{T}(\hat{z}, \hat{y})+\lambda_{e} S_{T}\left(z_{0}, \hat{y}\right)\right]\right\} .
\end{aligned}
$$

Notice that neither $U_{T-1}$ nor $V_{T-1}$ depend on the aggregate state of the economy $\psi$. Hence, we can write $U_{T-1}(y, \psi)=U_{T-1}(y)$ and $V_{T-1}(z, y, \psi)=V_{T-1}(z, y)$.

By repeating the above steps, it is straightforward to establish that the remaining equilibrium value and policy functions are uniquely determined by the equilibrium conditions (ii), (iii) and (iv) and that they are all independent of the aggregate state of the economy $\psi$. Hence, an equilibrium exists, is unique and it is block recursive. The proof of the efficiency of the equilibrium follows the same steps as the proof of part (iii) of Theorem 2 in Menzio and Shi (2011) and is therefore omitted. 
Table 1: Calibrated Parameters

\begin{tabular}{clc}
\hline \hline & Description & Value \\
\hline$\beta$ & discount factor & .9967 \\
$b$ & home productivity & 2.210 \\
\hline$k$ & vacancy cost & 23.03 \\
$\lambda_{u}$ & off the job search & 1.000 \\
$\lambda_{e}$ & on the job search & .6613 \\
$\delta$ & exogenous destruction & .0002 \\
\hline$\sigma$ & scale match productivity & 11.25 \\
$\phi$ & shape match productivity & 3.607 \\
$\alpha$ & match productivity learning & .2620 \\
$\eta$ & match productivity shock & .0094 \\
$\zeta$ & human capital function & 4.436 \\
$\psi$ & human capital function & .0112 \\
\hline
\end{tabular}

Table 2: Average Transitions

\begin{tabular}{llll}
\hline \hline & UE & EU & EE \\
\hline Data & .254 & .005 & .018 \\
Model & .261 & .006 & .015 \\
\hline
\end{tabular}

Table 3: Transitions by Tenure

\begin{tabular}{lcccc}
\hline \hline Tenure & EU data & EU model & EE data & EE model \\
\hline 4 months & .168 & .131 & .101 & .101 \\
8 months & .212 & .172 & .191 & .219 \\
12 months & .237 & .188 & .258 & .306 \\
2 years & .269 & .205 & .380 & .433 \\
5 years & .301 & .232 & .539 & .529 \\
\hline
\end{tabular}


Table 4: Log Wages by Age

\begin{tabular}{ccc|ccc}
\hline \hline Age & Data & Model & Age & Data & Model \\
\hline 21 & 0.7266 & 0.8003 & 42 & 1.3405 & 1.2933 \\
24 & 0.9180 & 1.0140 & 45 & 1.3615 & 1.3105 \\
27 & 1.0462 & 1.1166 & 48 & 1.3165 & 1.3256 \\
30 & 1.1444 & 1.1761 & 51 & 1.3632 & 1.3378 \\
33 & 1.2022 & 1.2168 & 54 & 1.4082 & 1.3471 \\
36 & 1.2848 & 1.2477 & 57 & 1.4082 & 1.3534 \\
39 & 1.3209 & 1.2726 & 60 & 1.3274 & 1.3567 \\
\hline
\end{tabular}

Figure 1: UE lifecycle profile

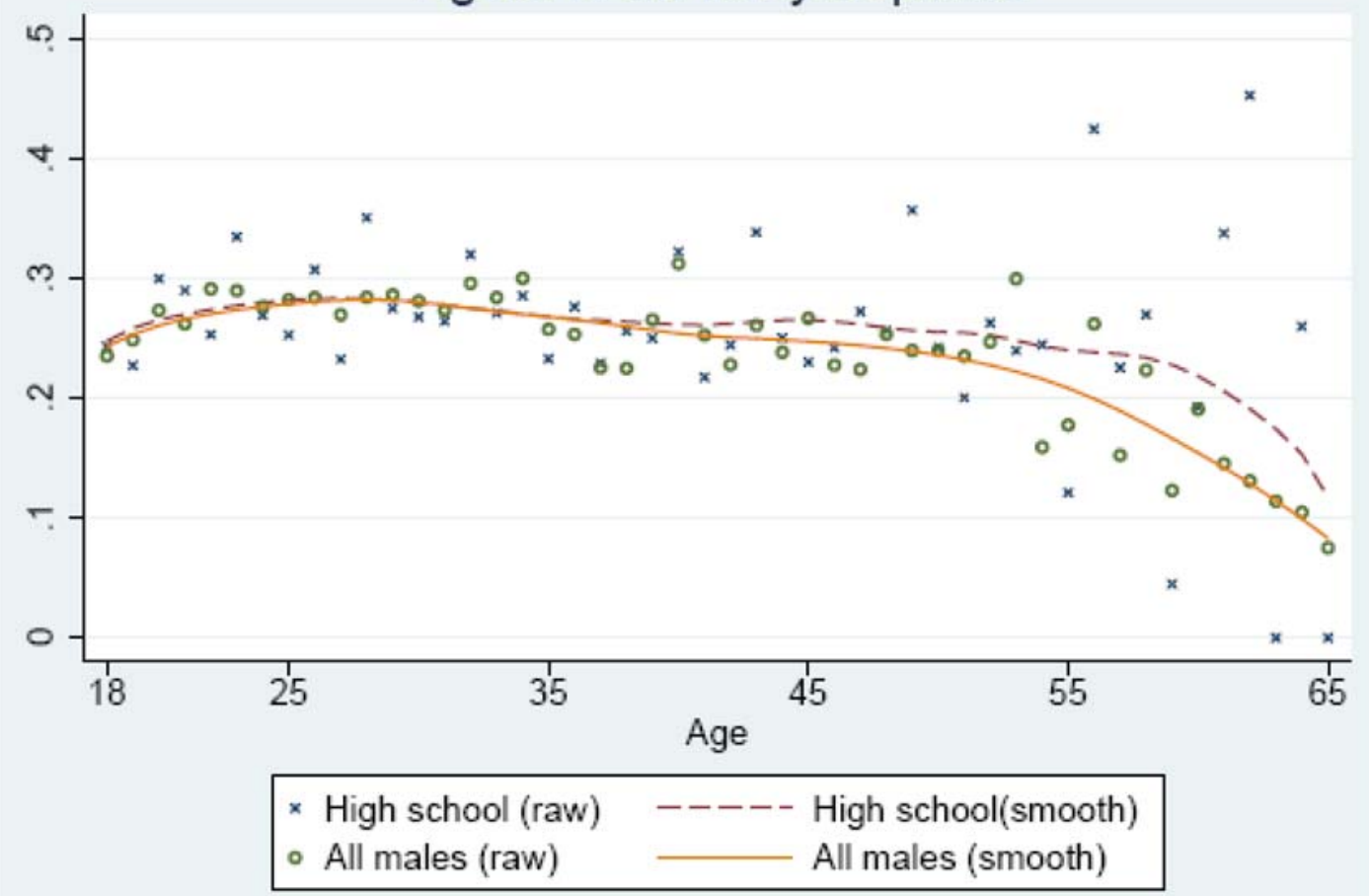


Figure 2: EU lifecycle profile

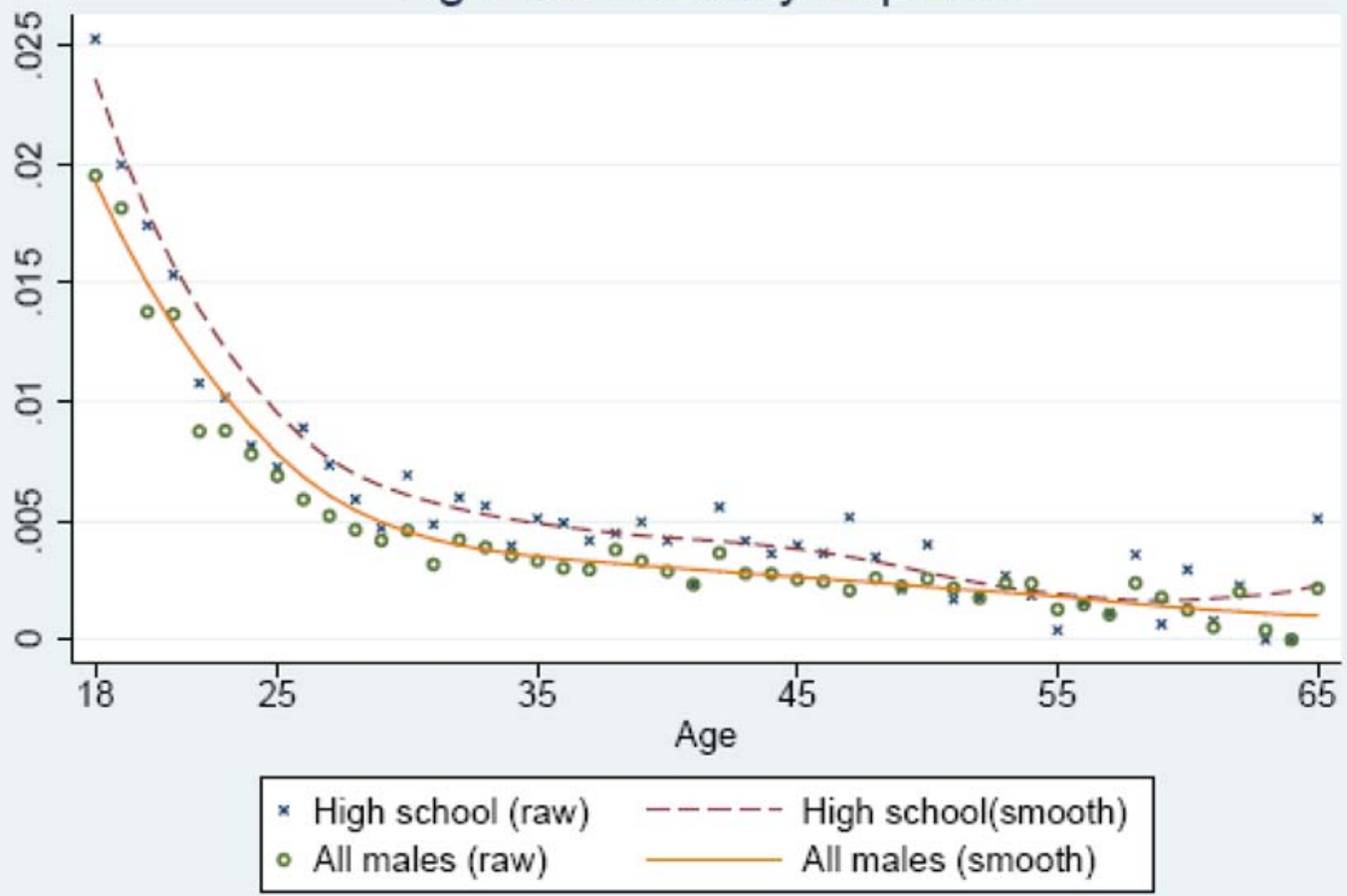

Figure 3: EE lifecycle profile

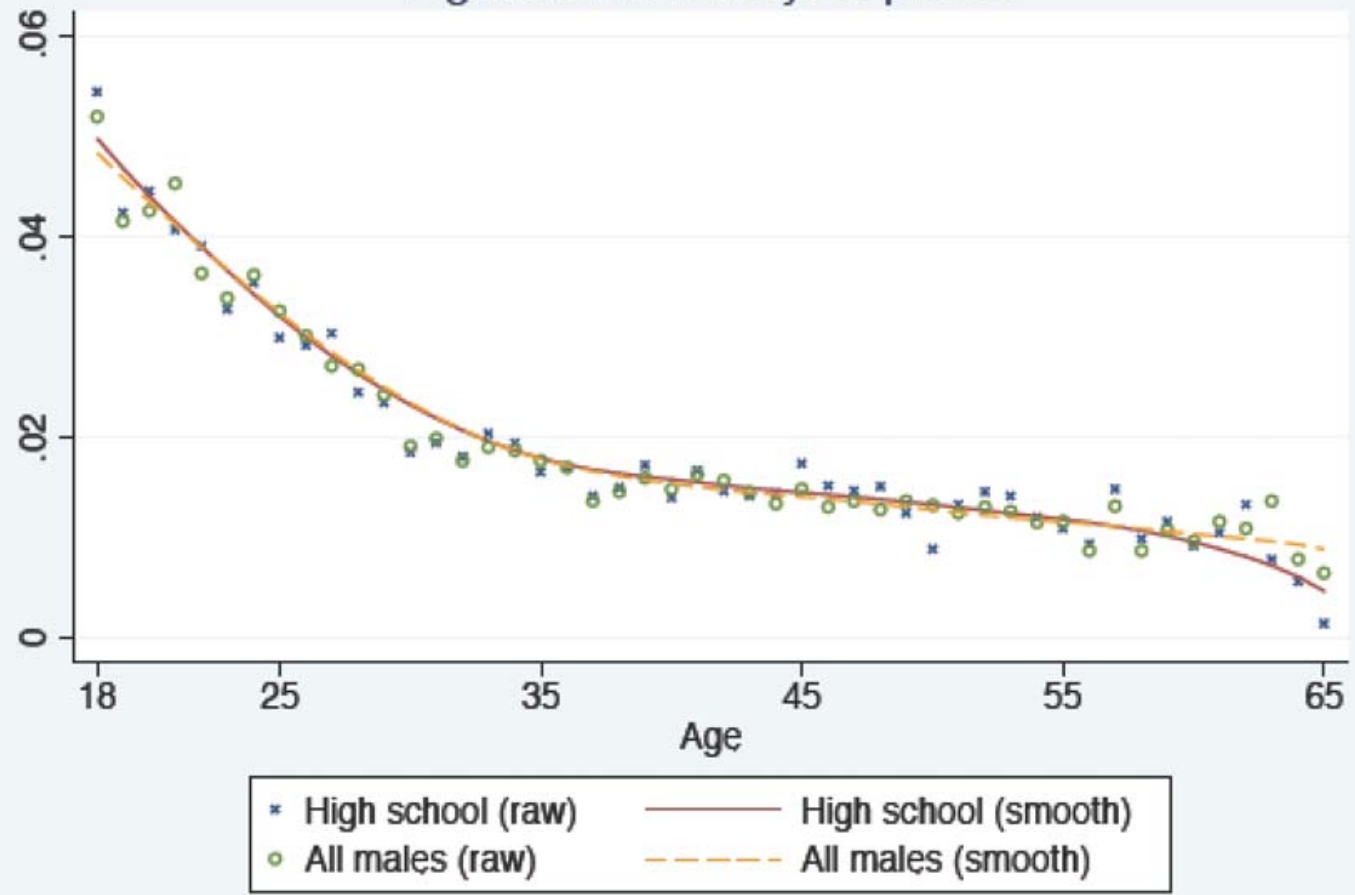



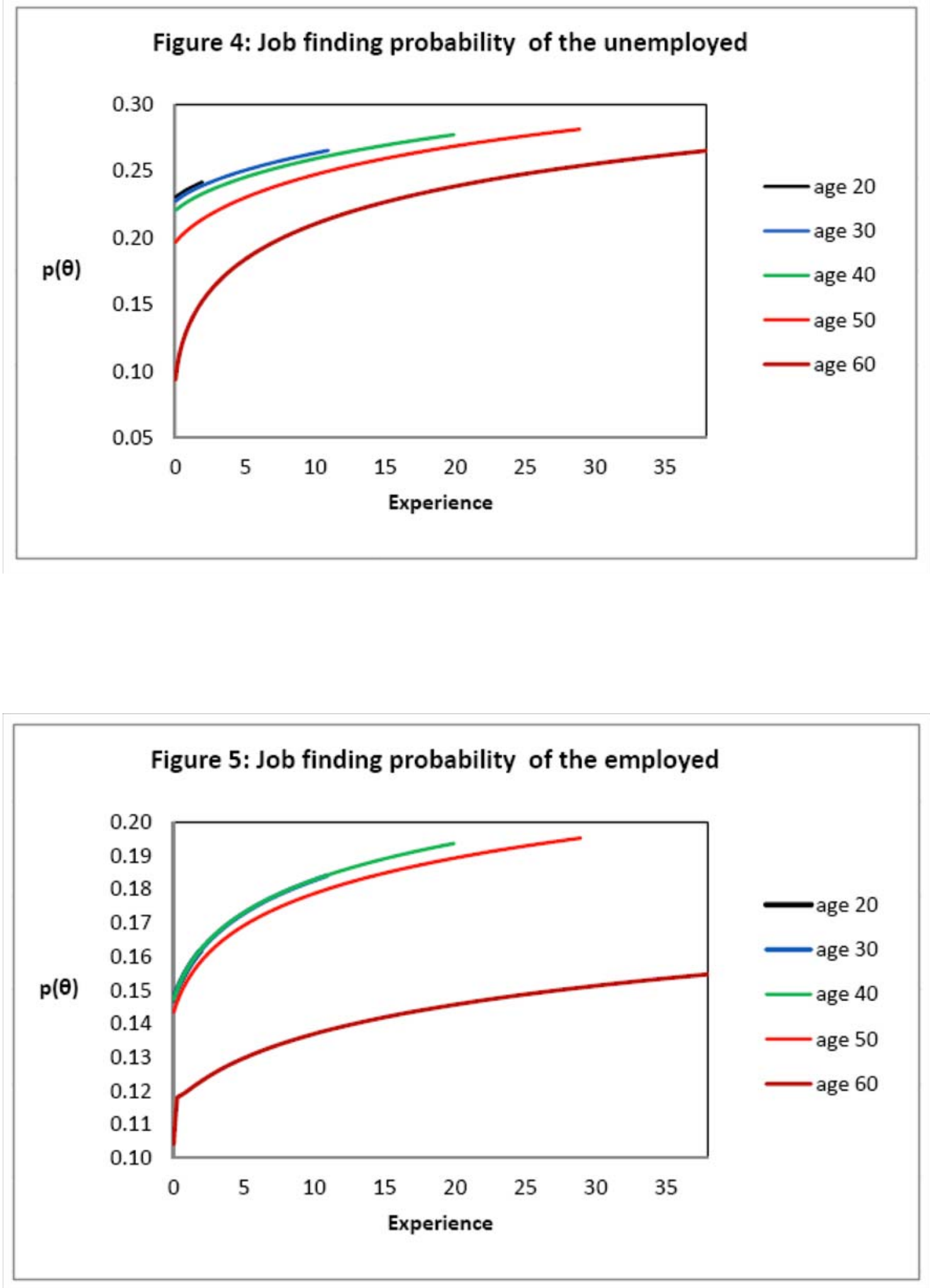


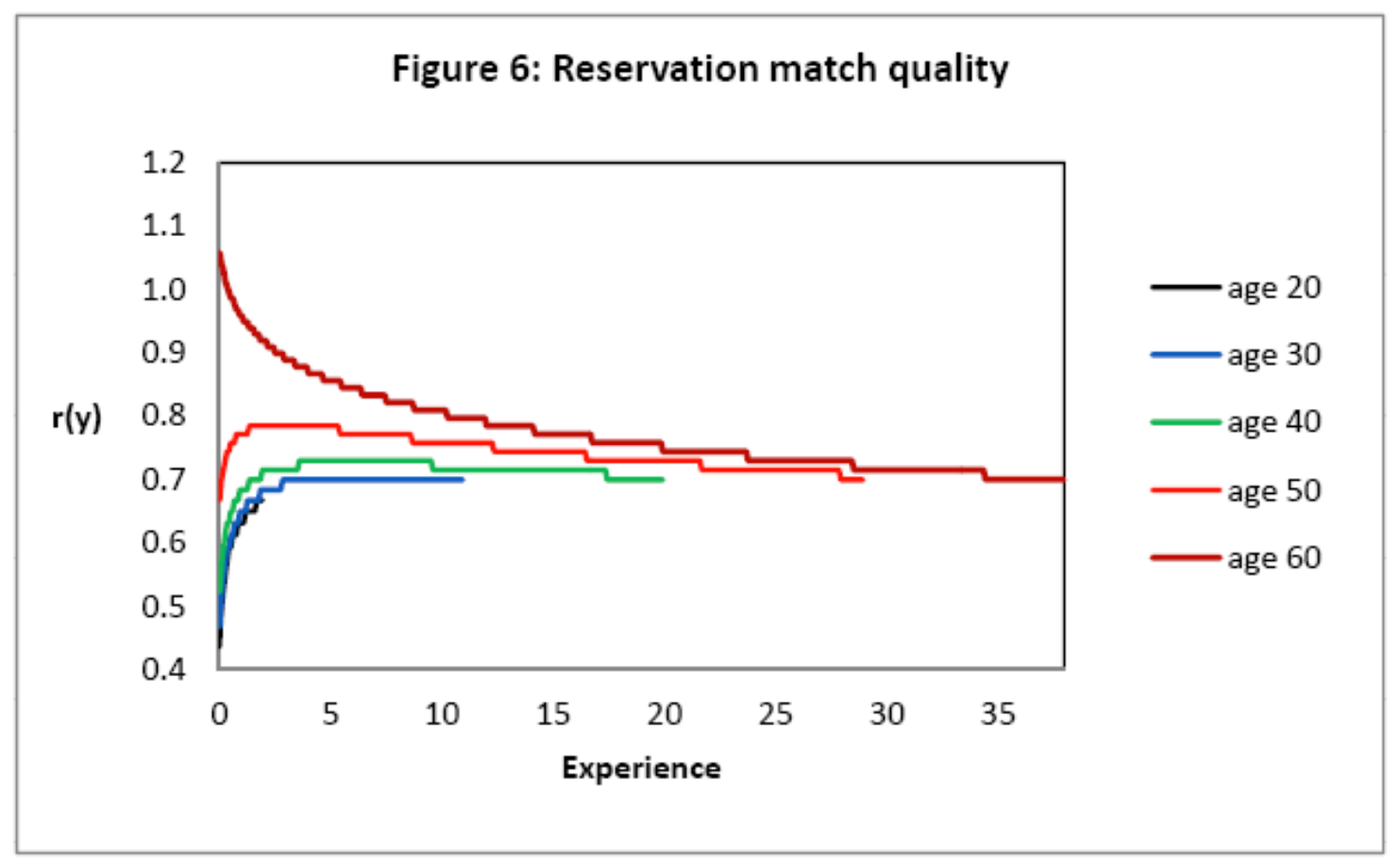

Figure 7: NL lifecycle profile

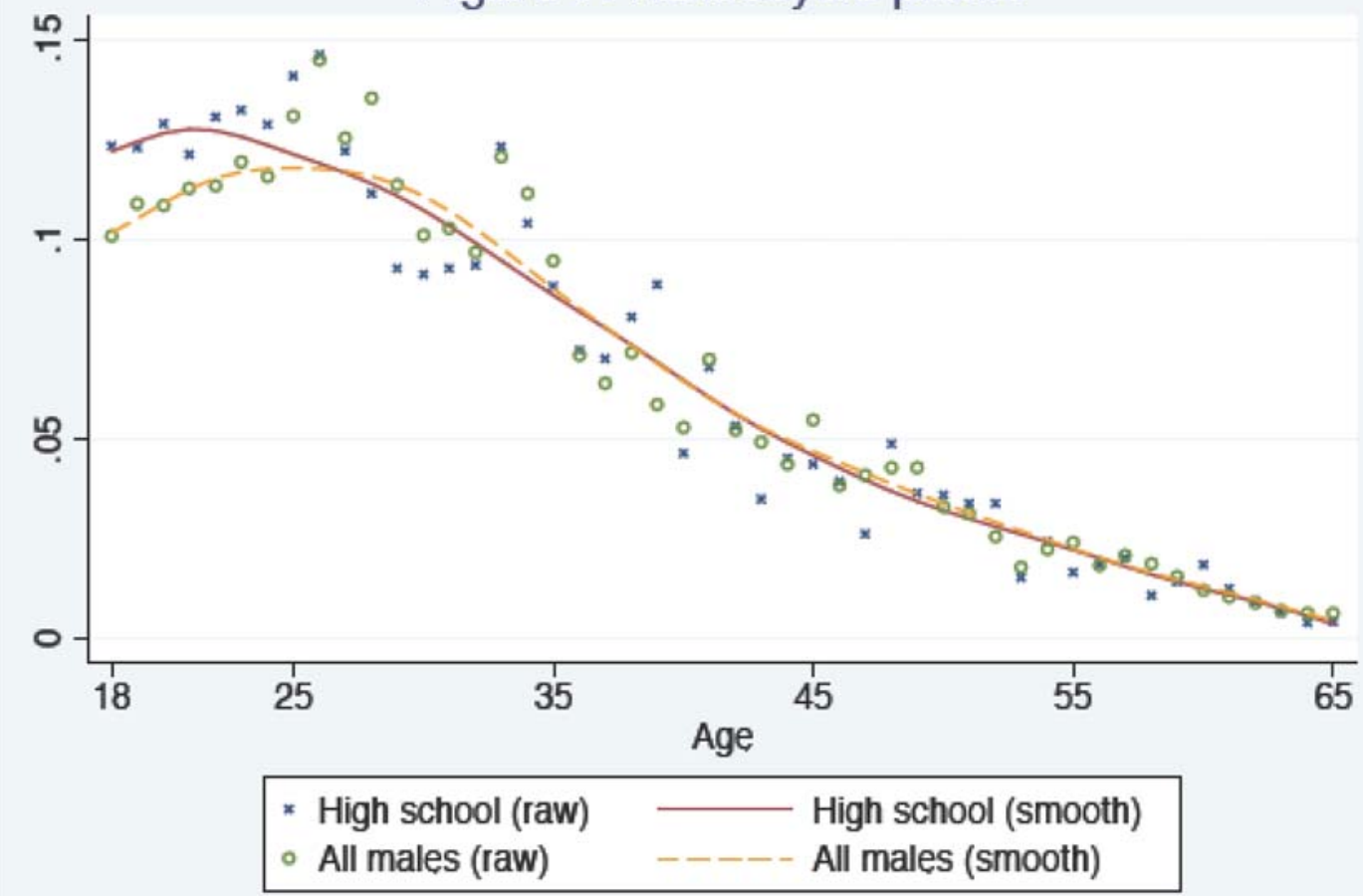


Figure 8: LN lifecycle profile

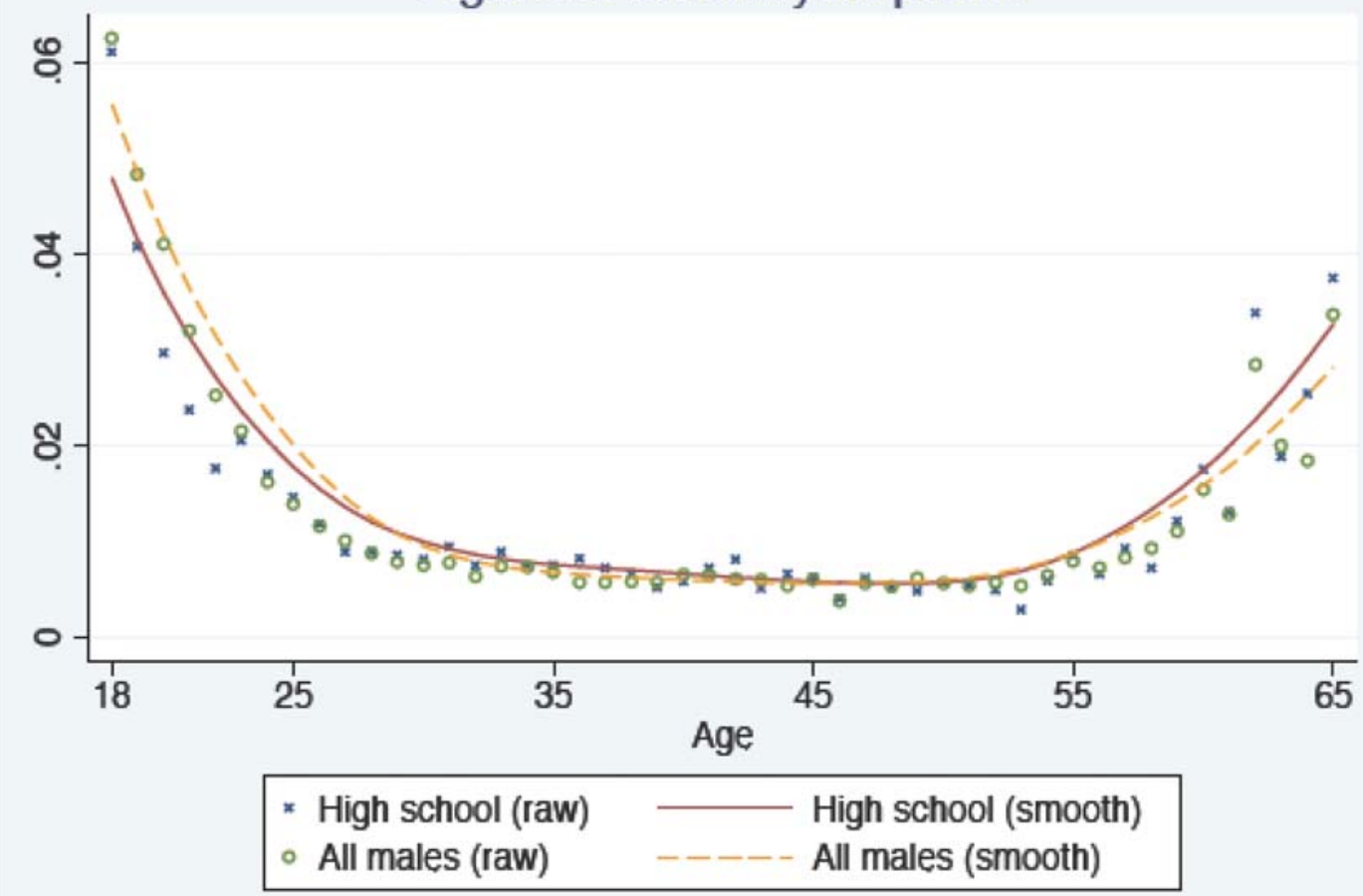

Figure 9: EU tenure profile

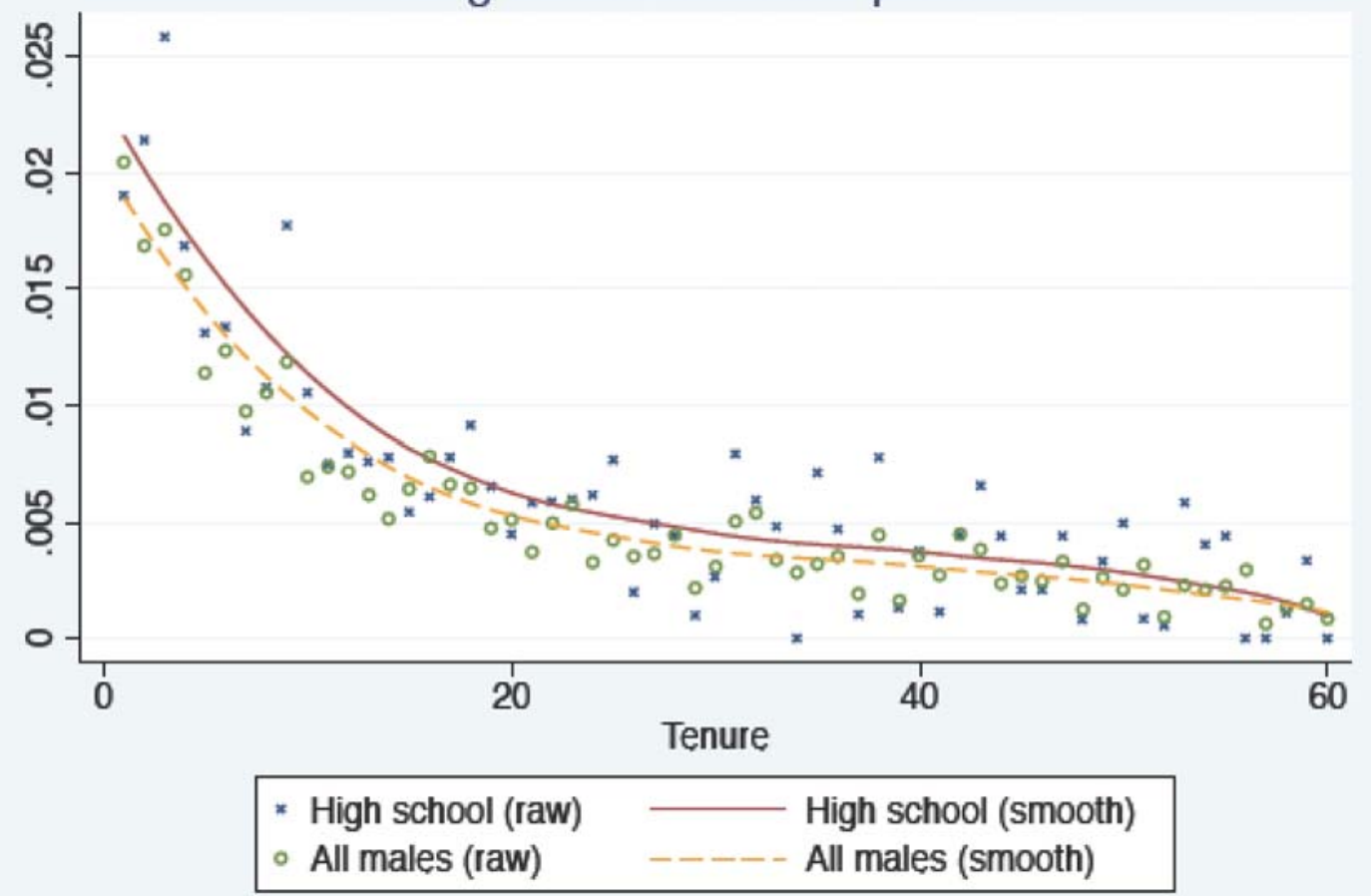




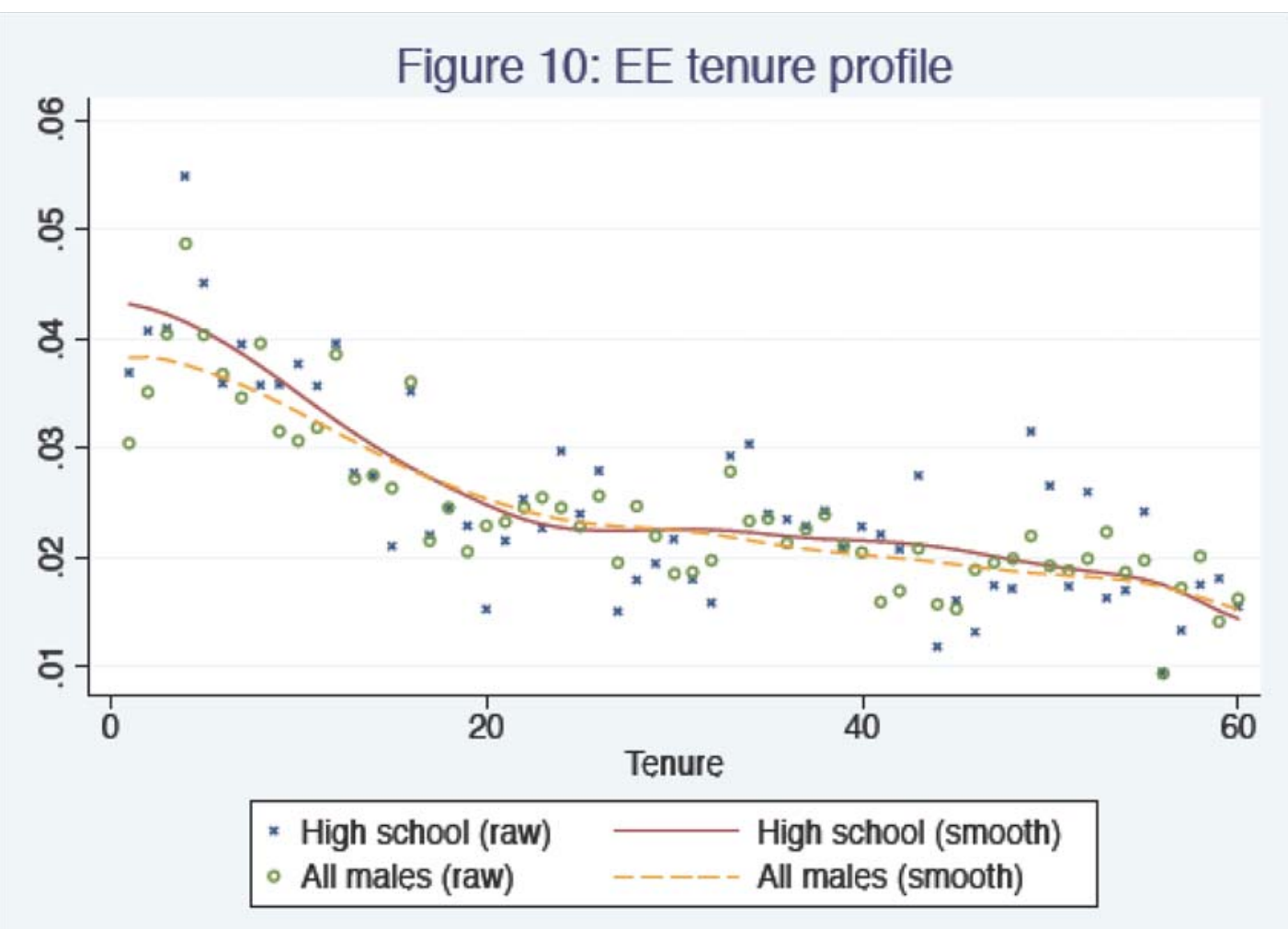

Figure 11: Wages lifecycle profile

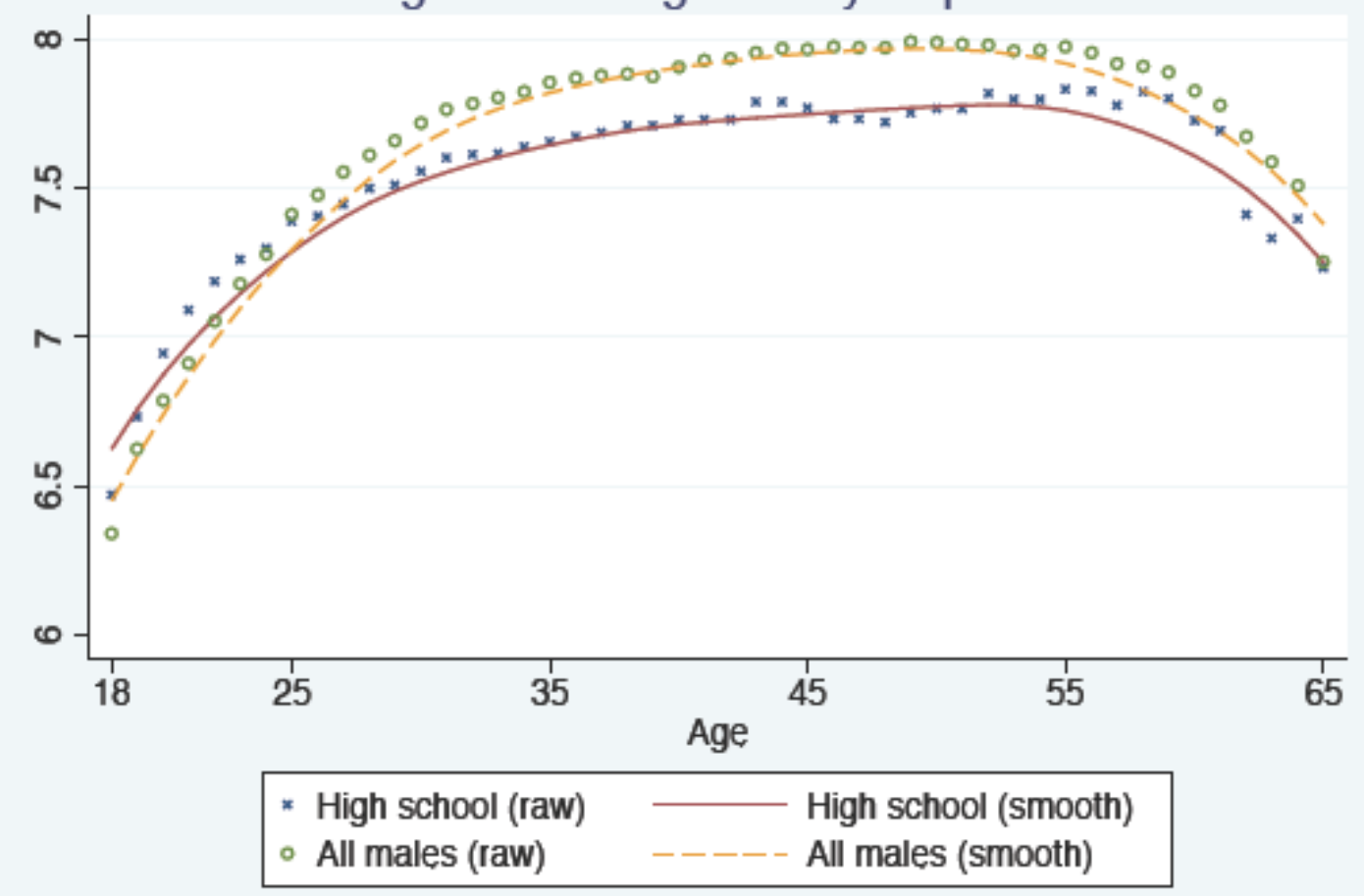


Figure 12: EE lifecycle profile

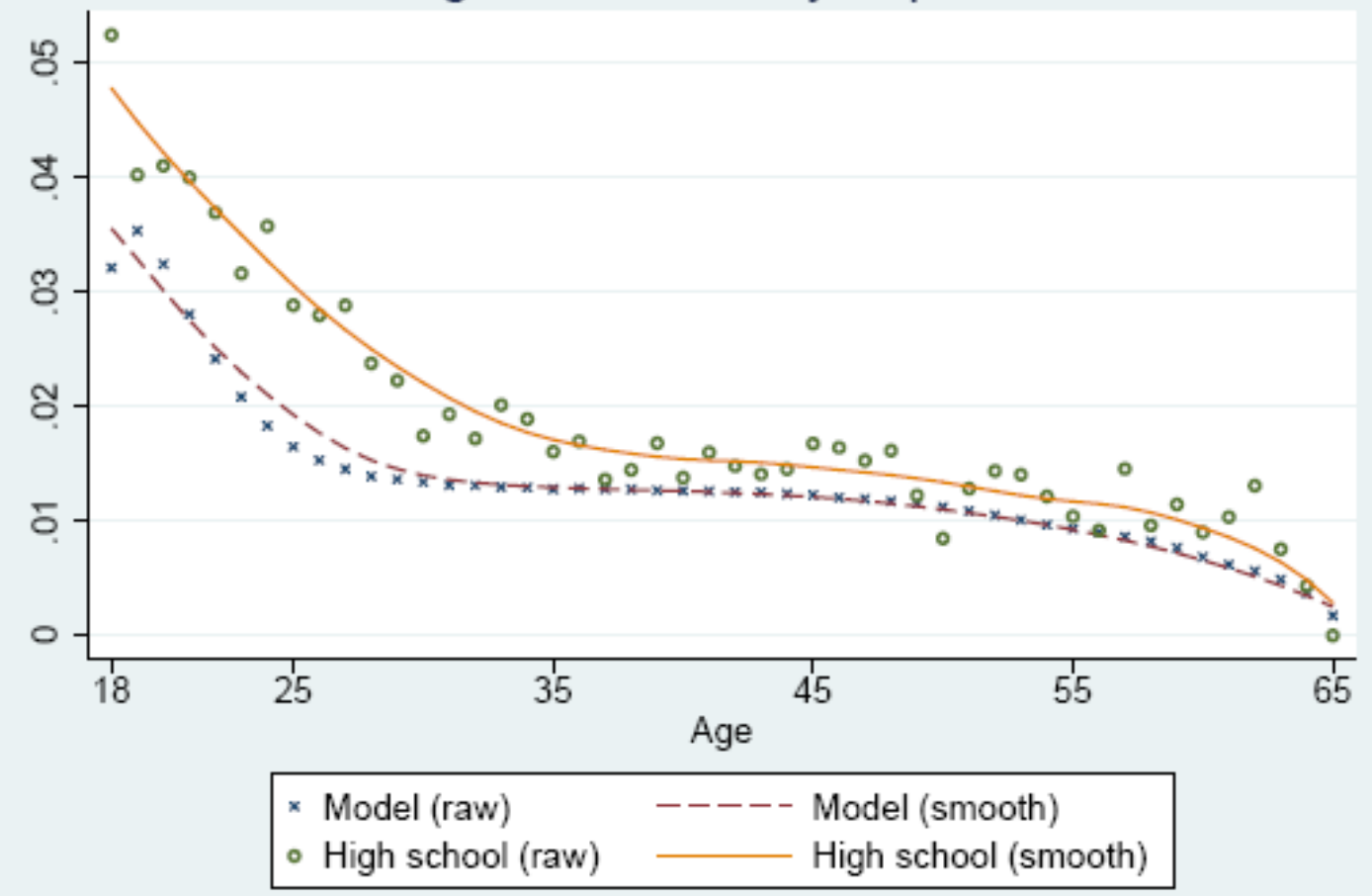

Figure 13: EE lifecycle decomposition

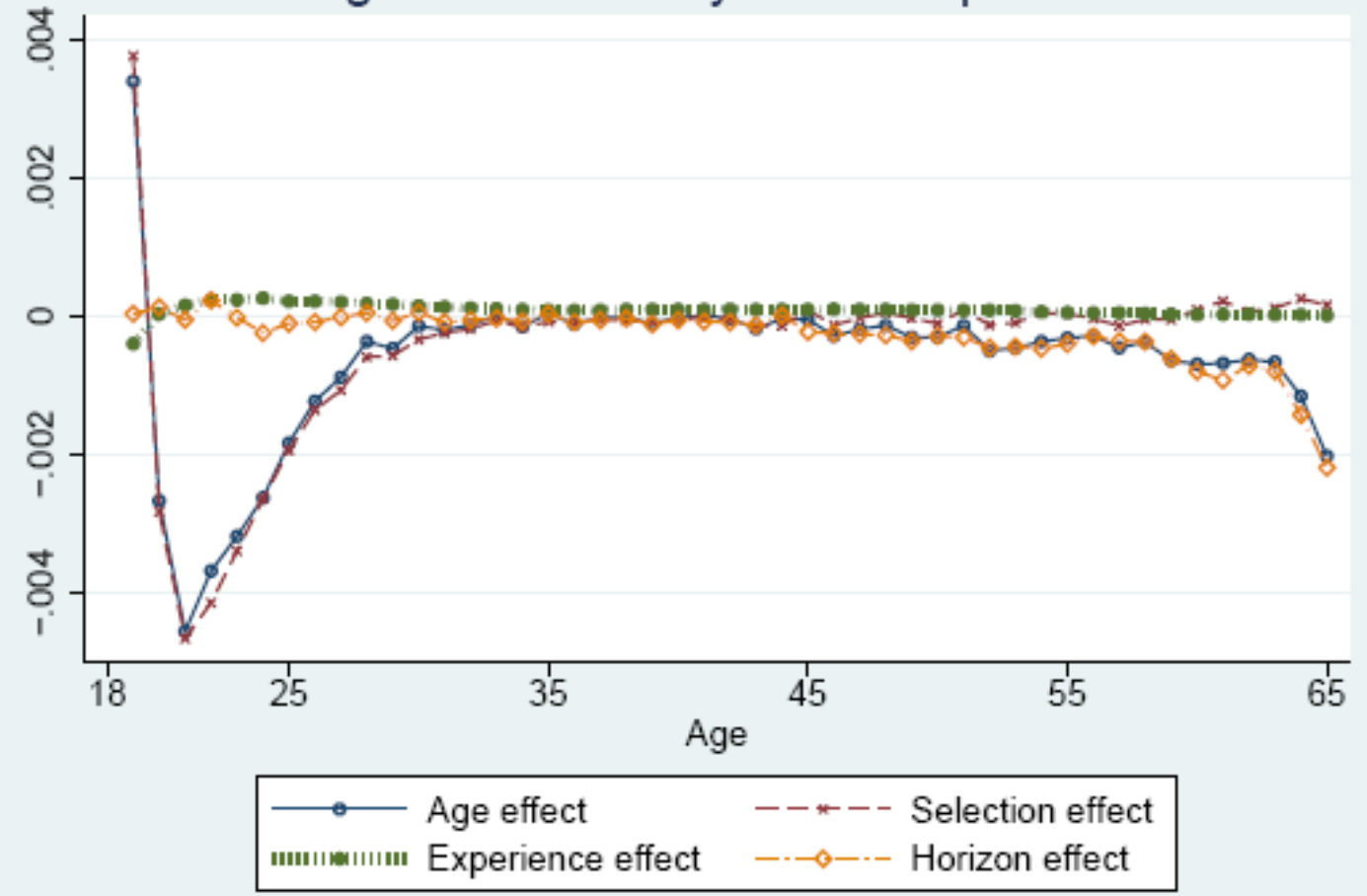


Figure 14: EU lifecycle profile

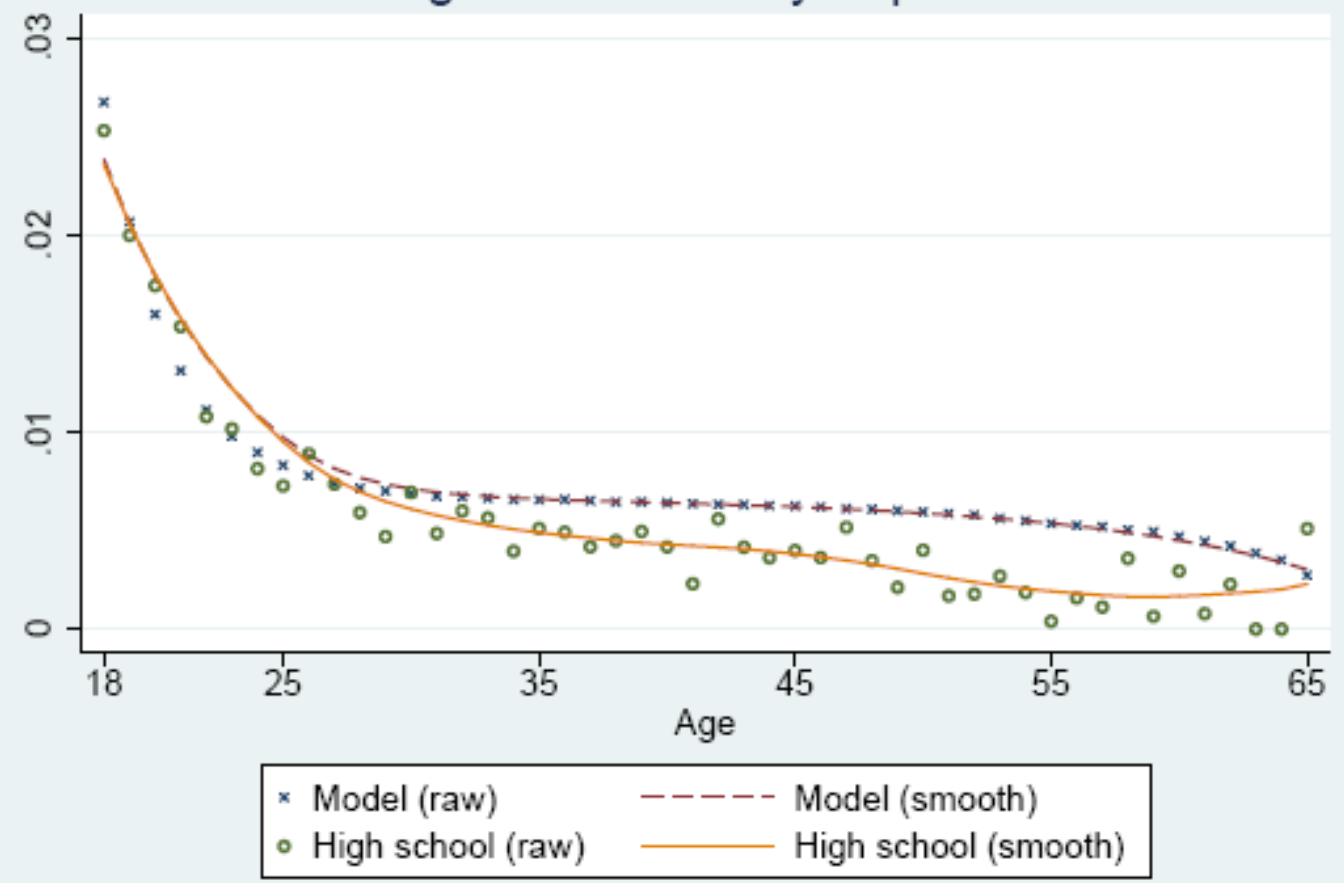

Figure 15: EU lifecycle decomposition

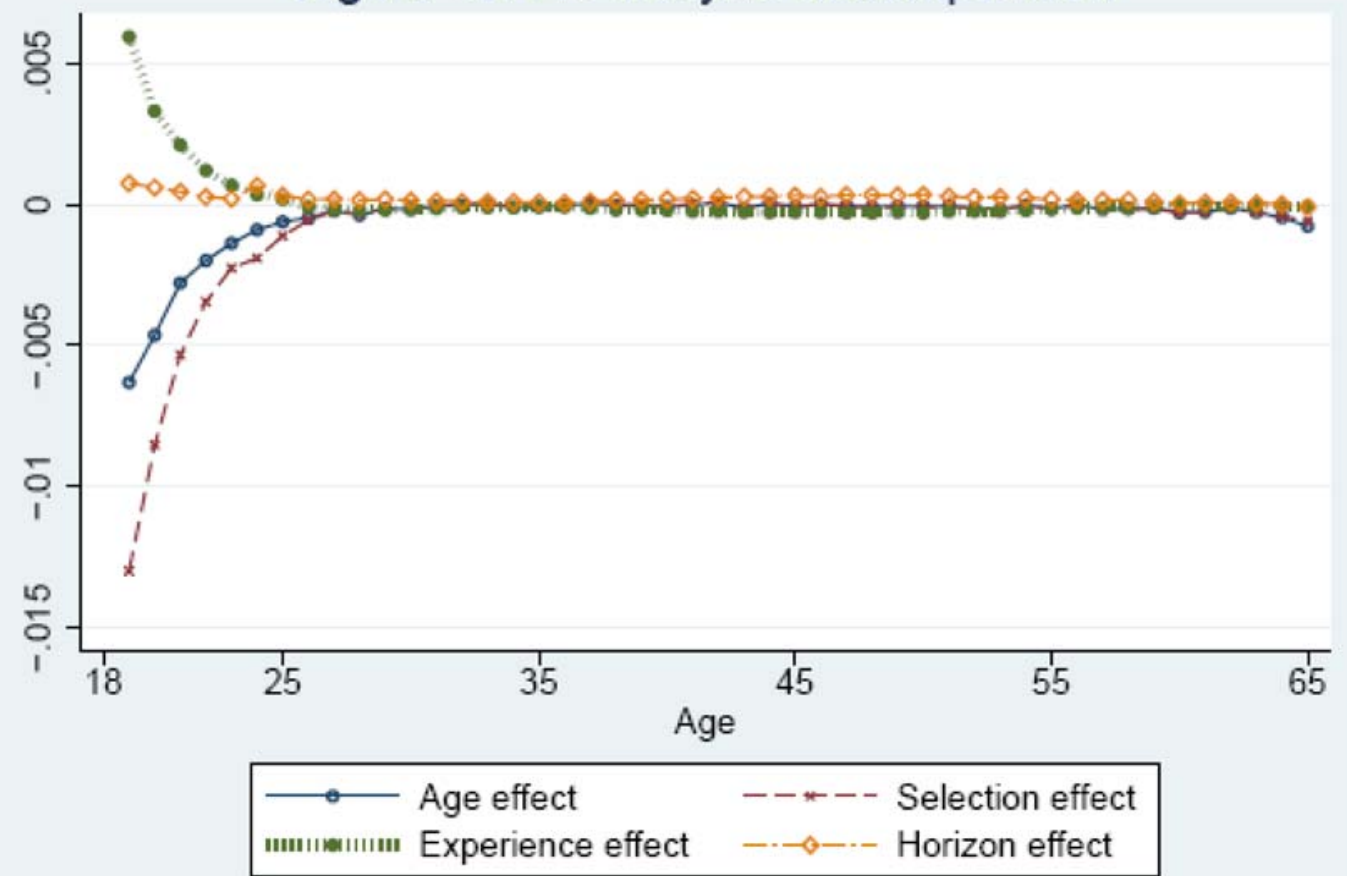


Figure 16: UE lifecycle profile

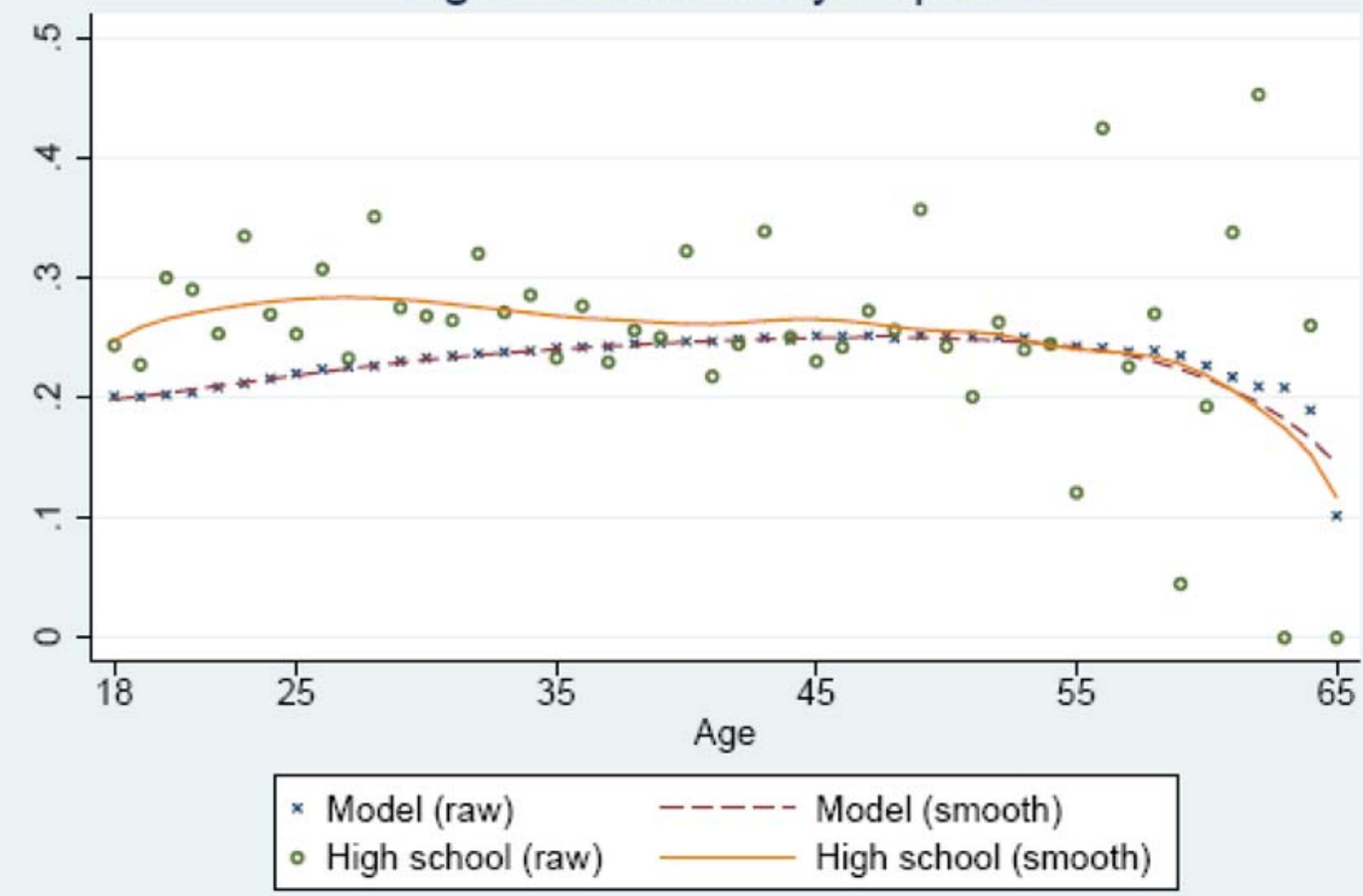

Figure 17: UE lifecycle decomposition

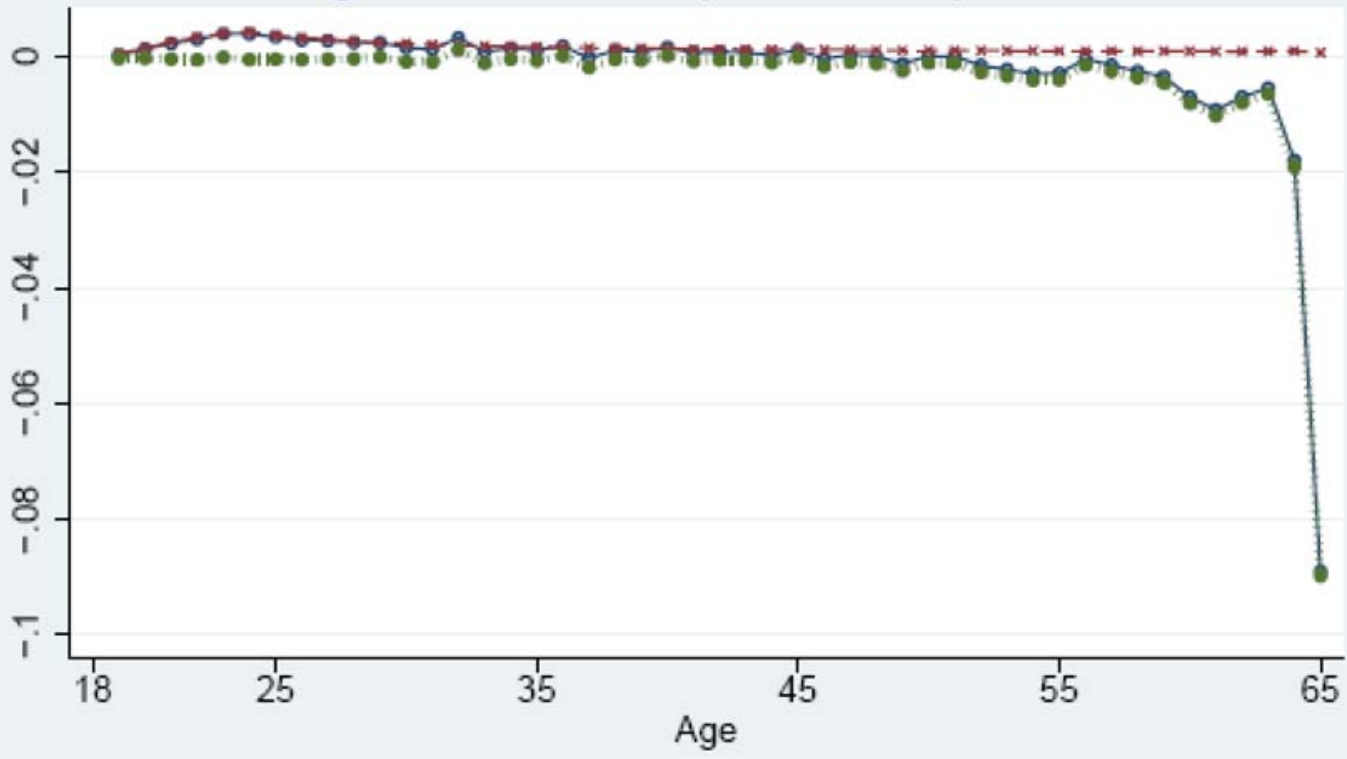

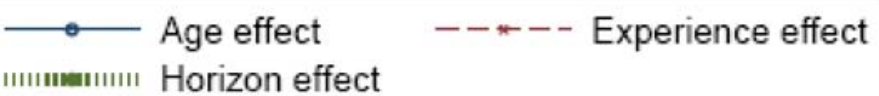




\section{Figure 18: Productivity growth decomposition}

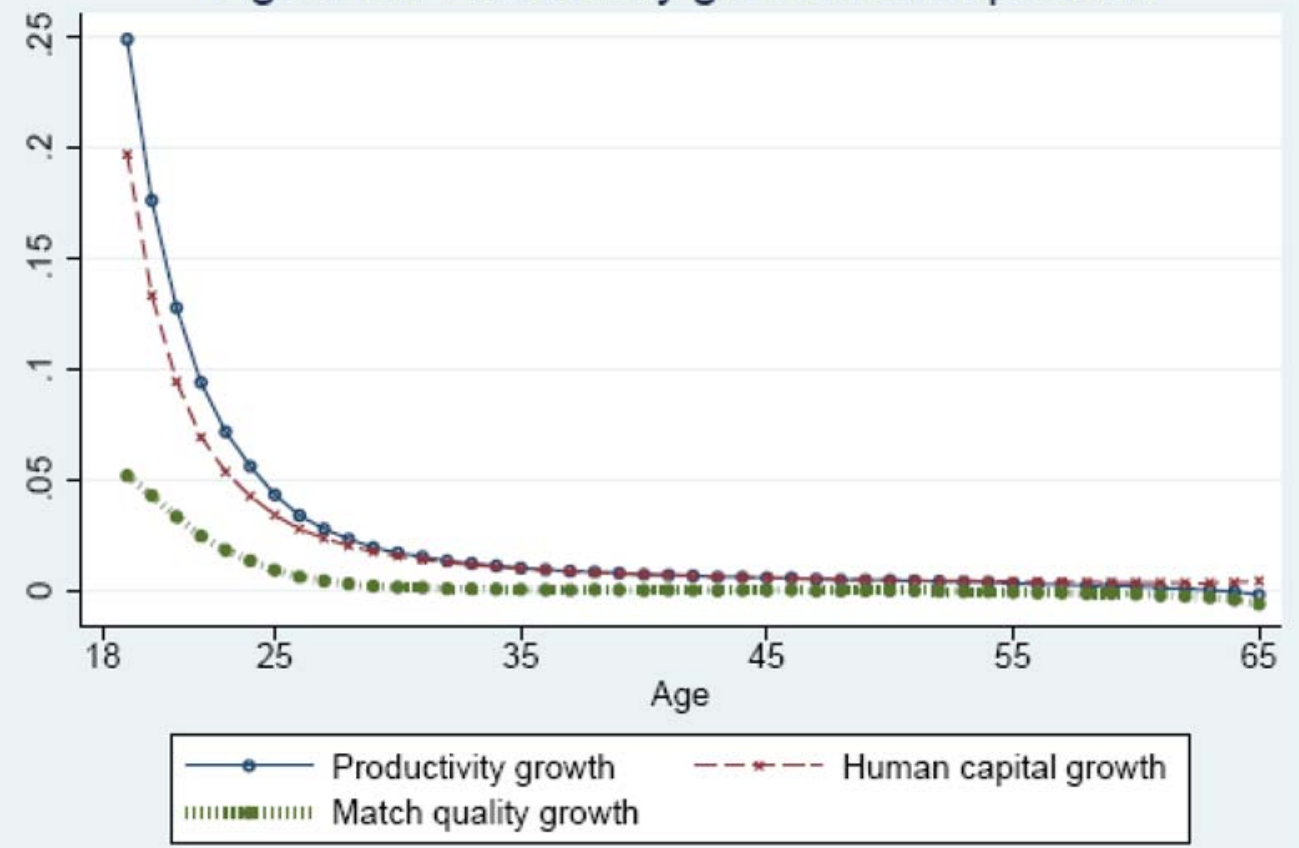

Figure 19: Wage growth decomposition

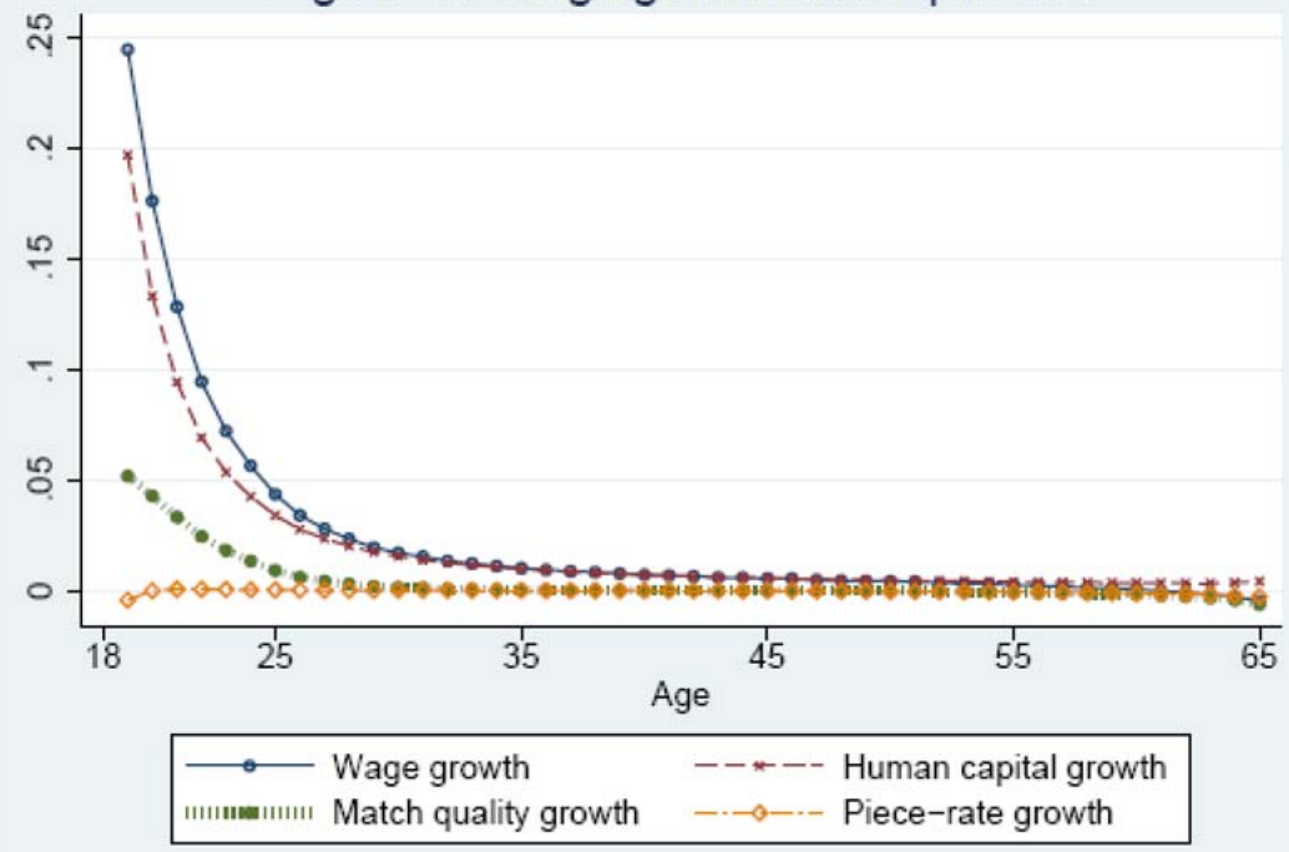

